\title{
An Observational and Model Characterization of Vertical Structure of Wind Fields over Eastern United States: A Case Study of Sterling, Virginia
}

\author{
Sium Gebremariam, ${ }^{1}$ Belay Demoz, ${ }^{1,2}$ Churchill Okonkwo, ${ }^{1,3}$ and Ricardo K. Sakai ${ }^{1}$ \\ ${ }^{1}$ Atmospheric Science Program, Beltsville Center for Climate System Observation, Howard University, 2355 6TH Street NW, \\ Washington, DC 20059, USA \\ ${ }^{2}$ Department of Physics, Joint Center for Earth Systems Technology (JCET), University of Maryland, Baltimore Campus, \\ 1000 Hilltop Circle, Room 424, Baltimore, MD 21228, USA \\ ${ }^{3}$ College of Online and Continuing Education, Southern New Hampshire University, 33 South Commercial Street, \\ Manchester, NH 03101, USA \\ Correspondence should be addressed to Sium Gebremariam; siumtesfai@gmail.com
}

Received 7 June 2015; Revised 30 September 2015; Accepted 30 September 2015

Academic Editor: Luis Gimeno

Copyright ( 2016 Sium Gebremariam et al. This is an open access article distributed under the Creative Commons Attribution License, which permits unrestricted use, distribution, and reproduction in any medium, provided the original work is properly cited.

The performance of twenty GCMs that participated in the Coupled Model Intercomparison Phase 5 (CMIP5) is evaluated at Sterling, Virginia, by comparing model outputs with radiosonde observational dataset and reanalysis dataset. We evaluated CMIP5 models in their ability to simulate wind climatology, seasonal cycle, interannual variability, and trends at the pressure levels from $850 \mathrm{hPa}$ to $30 \mathrm{hPa}$. We also addressed the question of the number of years required to detect statistically significant wind trends using radiosonde wind measurements. Our results show that CMIP5 models and reanalysis successfully reproduced the observed climatological annual mean zonal wind and wind speed vertical distribution. They also capture the observed seasonal zonal, meridional, and wind speed vertical distribution with stronger (weaker) wind during the winter (summer) season. However, there is some disagreement in the magnitude of vertical profiles among CMIP5 models, reanalysis, and radiosonde observation. Overall, the number of years to obtain statistically significant trend decreases with increasing pressure level except for upper troposphere. Although the vertical profile of interannual variability of CMIP5 models and reanalysis agree with the radiosonde observation, the wind trend is not statistically significant. This indicates that detection of trends on local scale is challenging because of small signal-to-noise ratio problems.

\section{Introduction}

A number of studies have evaluated the ability of climate model simulations that participated in Phase Five of Climate Model Intercomparison Project (CMIP5) to reproduce the observed features of North American continental and other regional climate features (e.g., [1-4]). These studies focused mainly on the surface and tropospheric climate change and their projections [5]. Specifically, [1, 2] emphasized how models represent (i) the mean state, variability, and longterm trends of basic climate variables (e.g., temperature, precipitation, and sea surface temperature) and (ii) large scale modes of climate variability (e.g., El Nino and the Southern
Oscillation, Pacific Decadal variability and Atlantic Multidecadal variability) and teleconnections with North American climate. Regional climate features analyzed in $[1,2]$ include, but are not limited to, North American Monsoon, the US Warming Hole, and Great Plains low level jet or drought. Overall, spatial pattern of basic climate is captured by the CMIP5 models while they have difficulty in reproducing the observed variability and teleconnections with North America climate $[1,2]$. On the other hand, while some regional climate features are reproduced by the models, other features are not, which might be associated with the coarse horizontal resolution of the models. For example, the midsummer drought in Central America is reproduced by most models 
while half of the models captured the observed intraseasonal variability in eastern Pacific [2].

Although several studies attempted to quantify the characteristics, variability, and mean state of the tropospheric jet streams (e.g., [6-8]), there is still inconsistency between observation and GCM models such as the lack of consensus in the magnitude of the poleward shift of jet stream and their future structure from GCMs (e.g., $[9,10])$. The large intermodel difference in poleward shift among GCMs deters us from having confidence in the GCMs use for projection [11].

This characterization is important in understanding the influence of stratospheric dynamics on tropospheric patterns [12]. The jet streams play an important role in the formation and development of middle-latitude cyclones and thus are crucial in the dynamical system of the troposphere [13]. Also, the characteristic poleward shifts in jet stream $[9,14]$ are being considered as potential indicators of climatic change.

Vautard et al. [15] analyzed upper air wind focusing on the northern hemisphere continental areas. They found that the upper level winds show different vertical profile of wind trends in different continental areas (Western Europe, North America, Central and East Asia, and China), although the cause of region to region difference in the vertical wind profile has not been addressed. Equivalently, [16] analyzed the radiosonde wind observation made from Macquarie Island $\left(54^{\circ} \mathrm{S}, 158^{\circ} \mathrm{E}\right)$ and compared these with newer version of European Centre for Medium-Range Weather Forecasts Reanalysis, namely, ERA-Interim reanalysis dataset. They found high (moderate) correlation between the near surface wind and upper level wind (Southern hemisphere Annular Mode) from Macquarie Island (located at $54.62^{\circ} \mathrm{S}, 158.85^{\circ} \mathrm{E}$ ) radiosonde dataset and ERA-Interim dataset. Southern Annular mode is large scale climate variability at mid and high latitudes in the southern hemisphere.

Recently, there has been growing interest in accurately depicting upper air winds due to their role in estimating the state and changes in general atmospheric circulation [15]. However, assessment of upper air wind trends is being hindered by insufficient studies on systematic trend analysis of radiosonde winds. Also, the investigations of annual and seasonal characteristics of wind over the whole atmospheric column are limited in climate literature. This is crucial since wind is an important parameter in the characterization of the dynamics of vertical profile of atmosphere [17].

The objective of this study is therefore to characterize and understand the vertical distribution of zonal, meridional, and wind speeds (wind fields) over Sterling, Virginia, Eastern United State of America. We will focus on the trend and variability at the tropospheric jet core. We will also calculate the number of years needed to detect future wind field trends from radiosonde observation.

This paper is organized as follows; the dataset and study approach are described in Section 2. Results from radiosonde and model comparison at Sterling, VA, National Weather Station, will be given in Section 3. The question of the number of years required to detect statistically significant wind trends from radiosonde observation is addressed in Section 4 followed by summary.

\section{Data and Methods}

2.1. Reanalysis and Radiosonde Observation. Three reanalysis datasets used in this study are NCEP-NCAR [18], NCEP-DOE [19], and ERA-Interim [20]. Both NCEP-NCAR and NCEPDOE (referred to henceforth as NCEP) have a horizontal resolution of $2.5^{\circ} \times 2.5^{\circ}$ with 28 vertical levels while ERAInterim reanalysis has a horizontal resolution of $1.5^{\circ} \times 1.5^{\circ}$ with 60 vertical levels. Data from ERA-Interim have been regridded using a bilinear interpolation method to a horizontal resolution of $2.5^{\circ} \times 2.5^{\circ}$ to simplify the intercomparisons. It is worth noting that the difference between the NCEP and ERA-Interim reanalysis is not limited to the physical parameterizations and resolution of the numerical forecast models they employ [18-20]. The reanalysis data differ also in the assimilation techniques they use. While NCEP reanalysis uses $3 \mathrm{D}$ variation assimilation technique, ERA-Interim reanalysis uses $4 \mathrm{D}$ variation assimilation technique. Improvements in these reanalysis products have been achieved through assimilations of many observation datasets (e.g., satellite observation since 1979), better assimilation technique, and better parameterization of many atmospheric processes in the model. For example, stratospheric circulation is now better represented by ERA-Interim reanalysis product relative to the ERA-40 reanalysis dataset [20]. Inclusion of satellite observation in reanalysis from 1979 shows some improvement in reanalysis especially over southern hemisphere where observations were scarce. Therefore, we focused our analysis from 1979 to 2005 , the period for which satellite information was assimilated in reanalysis.

Monthly mean zonal, meridional, and wind speed data (wind fields) from Sterling, Virginia, (located at latitude $38^{\circ} 58^{\prime} 36^{\prime \prime} \mathrm{N}$, longitude $77^{\circ} 29^{\prime} 09^{\prime \prime}$ east at an elevation of 88.4 meters above mean sea level) which is part of Integrated Global Archive (IGRA) radiosonde observations [21] are used to evaluate the reanalysis dataset and CMIP5 model simulations. The IGRA radiosonde observations contain high quality controlled upper air wind speed, wind direction, pressure, dew point depression, and relative humidity dataset spanning from 1950s to present. Most of the IGRA radiosonde observations have been assimilated in to reanalysis. Therefore, reanalysis and radiosonde observation are not independent dataset. Comparison of models, reanalysis, and radiosonde observation will provide assessment of model error and assimilation procedures used in the reanalysis. An important concern of radiosonde observation is that these datasets still suffer from inhomogeneity issues temporally (e.g., due to changes in instruments and time of observations) and spatially (e.g., less dense radiosonde observations in Southern hemisphere, tropics, and oceanic regions). For example, different radiosondes have been flown at Sterling station (e.g., VIZ A (1958-1988), VIZ B radiosonde (19881995), Vaisala RS80 radiosonde (1995-2005), and Microsonde MKIIA GPS equipped radiosonde (1995-present)). Thus, the trend and variability estimated from IGRA should be investigated and interpreted with caution [21].

2.2. Climate Model Data. Wind fields data from CMIP5 model simulations used in this study are summarized in 
TABLE 1: List of CMIP5 models used in this study. Models in bold are those CMIP5 models that have at least five ensemble members for both historical and future (RCP4.5) simulations.

\begin{tabular}{|c|c|c|c|c|}
\hline \multirow{2}{*}{ Institute (modeling group), country } & \multirow{2}{*}{ Models } & \multirow{2}{*}{$\begin{array}{l}\text { Ensemble } \\
\text { members }\end{array}$} & \multicolumn{2}{|c|}{ Atmospheric resolutions } \\
\hline & & & Horizontal (lon. $\times$ lat.) & Vertical levels \\
\hline $\begin{array}{l}\text { College of Global Change and Earth System Science, } \\
\text { Beijing Normal University, China }\end{array}$ & BNU-ESM & 1 & $2.8 \times 2.8$ & 26 \\
\hline \multirow{2}{*}{$\begin{array}{l}\text { Canadian Centre for Climate Modelling and Analysis, } \\
\text { Canada }\end{array}$} & CanCM4 & 10 & $2.8 \times 2.8$ & 35 \\
\hline & CanESM2 & 5 & $2.8 \times 2.8$ & 35 \\
\hline National Center for Atmospheric Research, USA & CCSM4 & 6 & $1.25 \times 0.94$ & 27 \\
\hline $\begin{array}{l}\text { Centro Euro-Mediterraneo per I Cambiamenti } \\
\text { Climatici, Italy }\end{array}$ & CMCC-CMS & 1 & $0.75 \times 0.75$ & 95 \\
\hline $\begin{array}{l}\text { Commonwealth Scientific and Industrial Research } \\
\text { Organisation in collaboration with the Queensland } \\
\text { Climate Change Centre of Excellence, Australia }\end{array}$ & CSIRO-MK3.6 & 10 & $1.8 \times 1.8$ & 18 \\
\hline \multirow{4}{*}{ Geophysical Fluid Dynamics Laboratory, USA } & GFDL-ESM2G & 1 & $2.5 \times 2.0$ & 24 \\
\hline & GFDL-ESM2M & 1 & $2.5 \times 2.0$ & 24 \\
\hline & GFDL-CM3 & 1 & $2.5 \times 2.0$ & 48 \\
\hline & GFDL-CM2p1 & 10 & $2.5 \times 2.0$ & 24 \\
\hline \multirow{2}{*}{ NASA Goddard Institute for Space Studies, USA } & GISS-E2-H & 5 & $2.5 \times 2.0$ & 40 \\
\hline & GISS-E2-R & 5 & $2.5 \times 2.0$ & 40 \\
\hline Met Office Hadley Centre, UK & HadCM3 & 10 & $3.75 \times 2.5$ & 19 \\
\hline \multirow{3}{*}{ Institut Pierre-Simon Laplace, France } & IPSL-CM5A-LR & 1 & $3.75 \times 1.875$ & 39 \\
\hline & IPSL-CM5A-MR & 1 & $2.5 \times 1.25$ & 39 \\
\hline & IPSL-CM5B-LR & 1 & $3.75 \times 1.875$ & 39 \\
\hline \multirow{3}{*}{$\begin{array}{l}\text { Japan Agency for Marine-Earth Science and } \\
\text { Technology, Atmosphere and Ocean Research Institute } \\
\text { (The University of Tokyo), and National Institute for } \\
\text { Environmental Studies, Japan }\end{array}$} & & & & \\
\hline & MIROC-ESM & 1 & $2.8 \times 2.8$ & 80 \\
\hline & MIROC-ESM-CHEM & 1 & $2.8 \times 2.8$ & 80 \\
\hline \multirow{2}{*}{ Max Planck Institute for Meteorology, Germany } & MPI-ESM-LR & 1 & $1.9 \times 1.9$ & 47 \\
\hline & MPI-ESM-MR & 1 & $1.875 \times 1.875$ & 95 \\
\hline
\end{tabular}

Table 1 and a full description of the CMIP5 models and their design is given in [22]. Most of the historical CMIP5 model simulations span from mid-1800s to 2005. Although several studies have merged the historical CMIP5 model simulations with future simulations based on Representation Concentration Pathways (RCP) scenarios to construct a longer monthly mean dataset (e.g., [23, 24]), we restricted our analysis to the core period 1979-2005 to avoid introducing mismatch of the forcing [25]. The historical CMIP5 simulations are forced by historical time varying atmospheric compositions, greenhouse gases, volcanoes, aerosols, land cover, and the solar constant but the ocean model is used instead of time varying global sea surface temperature (SST) and sea ice distributions from observations. For RCP4.5 CMIP5 model simulations, the radiative forcing is assumed to increase and then stabilizes at about $4.5 \mathrm{~W} \mathrm{~m}^{-2}$ after year 2100 . Moreover, both historical and RCP4.5 future scenarios climate model simulations have multiple ensemble members, which differ only in their initial conditions, while the other forcing used in the models is held the same. In this study, monthly mean wind data from subset of CMIP5 models are analyzed. Among these models, 8 of them have at least five ensemble members for both historical and RCP4.5 future simulations. For example, Figure 1 shows Taylor diagram [26] for the simulated monthly zonal and meridional wind at $200 \mathrm{hPa}$ from CSIROMK3.6.0 as compared with the radiosonde observation.

This model has 10 ensemble members which differ only on the initial conditions of the atmospheric component. The radiosonde observation is taken as the reference and compared with the ten ensemble runs from CSIRO-Mk3.6.0 model in terms of correlation, standard deviation, and root mean square error, three comparison metrics in a single graph (Figures 1(a) and 1(b)). First the model skill in simulating the observed zonal and meridional monthly mean winds is generally low as indicated by lower correlation pattern and higher RMS error. In general, the correlation coefficients between observed and model simulated monthly mean wind are less than 0.7 for zonal wind while meridional wind has a correlation coefficient of less than 0.4 . This is not surprising because models are not expected to capture the internal (unforced) variability such as the correct timing of El Nino events, the North Atlantic Oscillation, and pacific decadal oscillation which are caused by the natural variability of the complex nonlinear climate system [22].

Second, our result shows that change in the initial condition has impact on zonal and meridional wind speed as indicated by the spread in the seasonal and annual correlation coefficient, RMS error, and standard deviation ratio between 


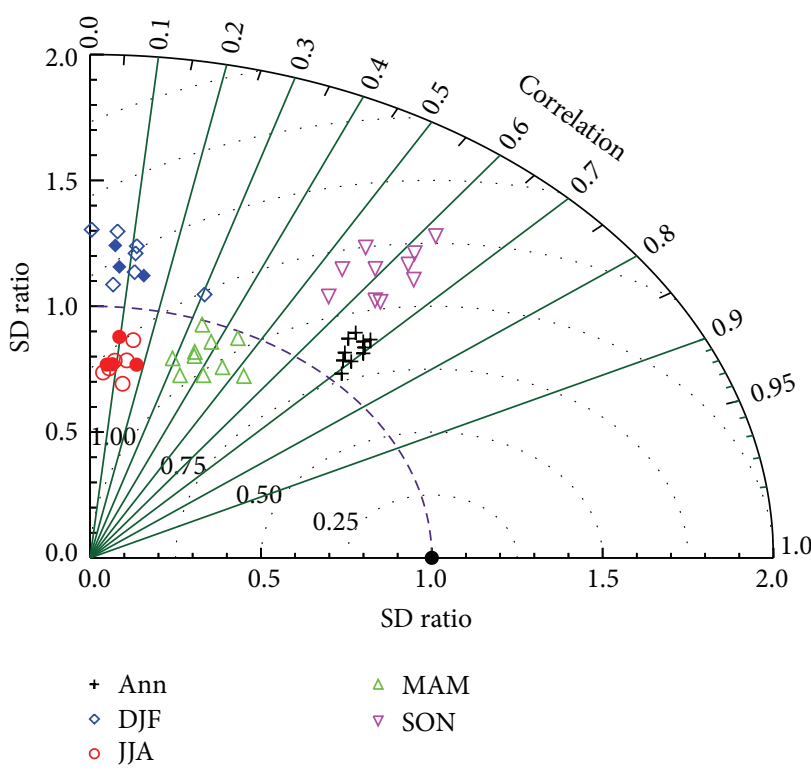

(a)

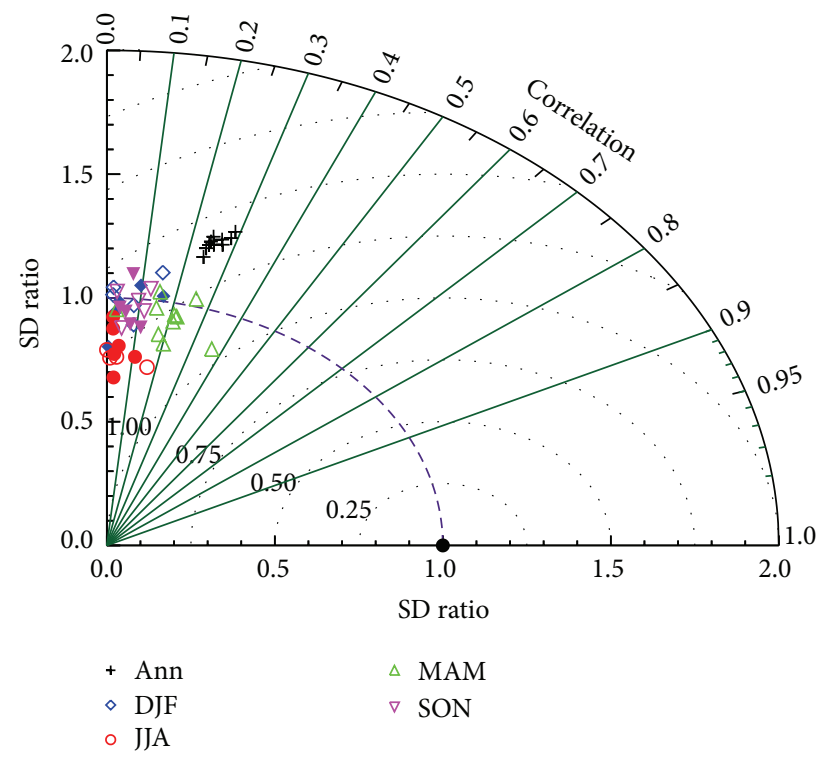

(b)

FIGURE 1: Taylor diagram is displayed in polar coordinate for pattern comparison between reference and other runs in terms of correlation, standard deviation (SD), and root mean square error (RMSE) for (a) zonal wind and (b) meridional wind. SD ratio is the standard deviation of each model run to that of the radiosonde observation taken as a reference. SD ratio is the radial distance from the origin; the RMSE is the distance to the reference point; the azimuthal position gives the correlation coefficient. The colored symbols represent monthly data used for each run from 1979 to 2005 (annual, black plus; December, January, and February (DJF), blue diamond; March, April, and May (MAM), green upward triangle; June, July, and August (JJA), red circle; September, October, and November (SON), magenta downward triangle). Open (filled) symbols represent positive (negative) correlations between each ensemble member and radiosonde observation (black filled circle).

observation and each run. The spread among individual simulations also indicates the uncertainty in the initial condition of CMIP5 models (initial condition problems). These uncertainties and errors are further analyzed in Section 2.4.

2.3. Method of Analysis: Trend Detection. The method consists of analysis of annual and seasonal zonal, meridional, and wind speed time series data from historical CMIP5 model simulations, reanalysis (ERA-Interim, NCEP/NCAR, and NCEP/DOE) product, and radiosonde observations. Trends are computed for each model, reanalysis product, and observations. Trend values are calculated using a linear least square analysis method. The trend uncertainty computing was based on standard error, taking into account the autocorrelation of the time series [27].

Since the CMIP5 simulations used in this study vary in resolution from $0.75^{\circ}$ latitude $\times 0.75^{\circ}$ longitude (Model CMCC-CMS) to $3.75^{\circ}$ latitude $\times 2.5^{\circ}$ longitude (Model HadCM3) as shown in Table 1 , each model is linearly interpolated to a common resolution (e.g., $2.5^{\circ}$ latitude $\times 2.5^{\circ}$ longitude horizontal resolution) to simplify the comparison between models and reanalysis.

Figure 2(a) shows interpolated CMIP5 horizontal resolution, radiosonde burst location at $50 \mathrm{hPa}$, and topography map. As shown in Figure 2(b), the radiosondes launches drift from Sterling station location and are within longitude ranging from $80^{\circ} \mathrm{W}$ to $75^{\circ} \mathrm{W}$ and latitude ranging from $37.5^{\circ} \mathrm{N}$ to $40^{\circ} \mathrm{N}$. Based on the trajectory of the radiosonde launches, wind data from two nearby grid boxes from CMIP5 and reanalysis product are first selected as a climatic representative of Sterling radiosonde station. Wind data from these preselected two nearby grid boxes are then averaged and compared with the Sterling radiosonde observation.

Finally, statistical technique given in (1) [28] has been utilized to address the question of number of years needed to determine statistically significant trend at $95 \%$ confidence level with the probability of 0.9 . One has

$$
n^{*}=\left[\frac{3.3 \sigma_{N}}{\left|\omega_{o}\right|} \sqrt{\frac{1+\Phi_{N}}{1-\Phi_{N}}}\right]^{2 / 3},
$$

where $n^{*}$ is the number of years needed to detect an expect trend $\left(\omega_{o}\right) \cdot \sigma_{N}$ and $\Phi_{N}$ are standard deviation and autocorrelation of wind speed time series noise, respectively. For details of this statistical technique, please see [28]. The method has been applied for a number of atmospheric variables including temperature, ozone, and water vapor time series. For example, [29] recently utilized the method to address the number of years required to detect water vapor trends in the upper troposphere $(200 \mathrm{hPa})$ at the Southern Great Plains site in northern Oklahoma. They concluded that it required at least 12 years of monitoring climate quality water vapor concentration from perfect observational data (i.e., observation of water vapor with no measurement uncertainty). They also recommended that it is essential to increase the frequency of water vapor measurements than 


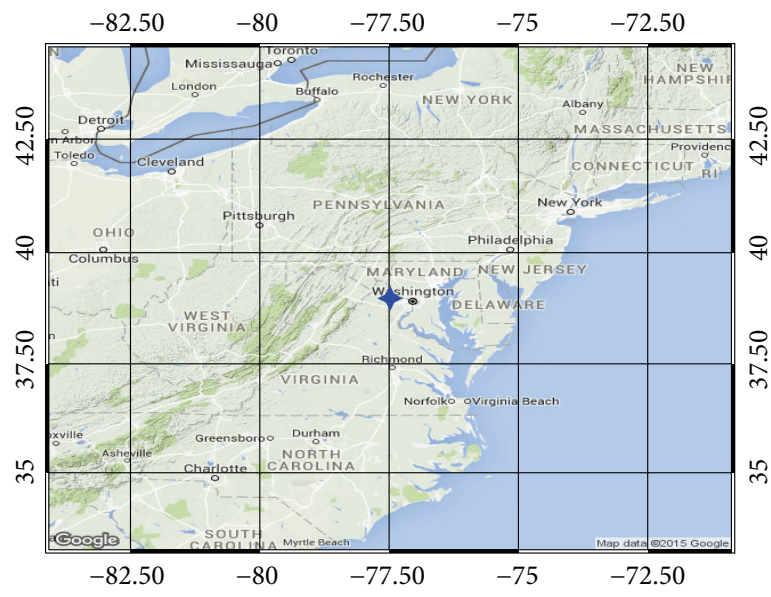

(a)

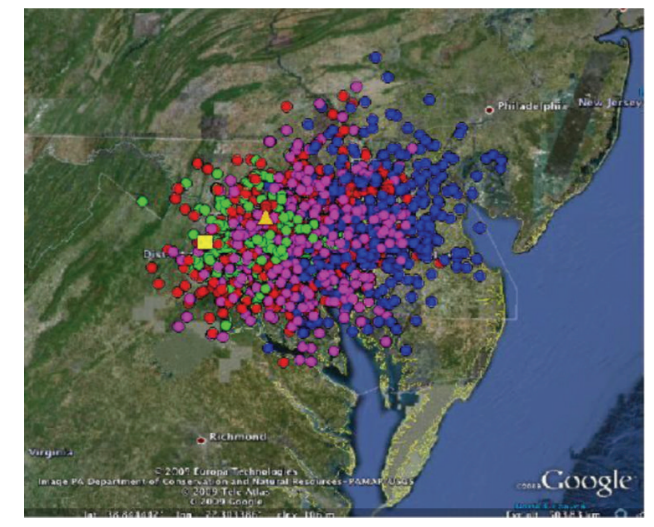

(b)

FIGURE 2: (a) Reanalysis and CMIP5 interpolated to $2.5^{\circ}$ by $2.5^{\circ}$ grid cells to compare with the radiosonde stations data (blue star represents the Sterling, VA, National Weather Station location). (b) Radiosonde burst location at $50 \mathrm{hPa}$ for the Sterling station. The circles in (b) represent JJA, SON, DJF, and MAM for green, red, blue, and purple, respectively, while yellow square and triangle represent Sterling radiosonde stations and Beltsville research site, respectively.

reducing the random error in measurements. In this study, we applied the same method for wind time series $(Y)$ which can be represented by the following equation:

$$
\begin{aligned}
& Y=\mu+\omega_{o} \frac{t}{12}+S+N, \\
& S=\sum_{j=1}^{4}\left(a_{j} \sin \frac{2 \pi j t}{12}+b_{j} \cos \frac{2 \pi j t}{12}\right),
\end{aligned}
$$

where $\mu$ is the climatology mean, $t$ is the time in months, $\omega_{o}$ is the trend magnitude $\left(\mathrm{m} \mathrm{s}^{-1}\right.$ year $\left.^{-1}\right), N$ is the monthly mean noise of the time series which is assumed to be autoregressive with lag of one month (AR1), and $S$ is the seasonal term (3) which are computed by fitting four harmonic function to the detrended monthly anomalies wind time series.

2.4. Uncertainty and Errors in Models and Reanalysis. Even with improvements in the performance of climate models in reproducing the present and past climate due to a combination of sophisticated physical parameterization and higher model resolution [30], there are still some discrepancies (e.g., $[24,31])$. There has thus been increasing interest in understanding, interpreting, and analyzing the probabilistic output from climate models [32]. This is much so since results from climate models are increasingly being used in formulation of climate change adaptation and mitigation policies.

Before we discuss the results from our study, we summarize in this section different sources of uncertainty in climate models, namely, forcing, initial condition, and model imperfection (model inadequacy and model uncertainty). According to [32], there are three main types of uncertainties: (1) forcing uncertainty refers to future effects, despite being outside, but can still affect the climate system, (2) initial conditions uncertainty captures uncertainties relating to initial state or ensemble state and forward integration in time, and
(3) uncertainties derived from the inadequate understanding of and ability to simulate the Earth's climate describe the model imperfections [32].

For reanalysis and observation, [33] noted that even with extensive enhancement due to inclusion of observational data and more accurate models, there are still some limitations and doubts. Other issues that can introduce errors and uncertainties in reanalysis include hitches in merging heterogeneous observations on a regular grid as well as quality of observational dataset being used [34]. An indication of flaws in these reanalysis data becomes clear with inconsistent results which is a pointer that at least one of the products is faulty (e.g., $[4,35,36])$.

According to [30], uncertainties in reanalysis are smaller than in model error with the exception of meridional components of upper atmospheric quantities. With no suitable observations available at upper atmosphere, analysis at these levels relies on reanalysis and model data.

To demonstrate an element of possible initial conditions (intramodel) and intermodel uncertainties in the models used in this study, we evaluated 8 models with 5 ensemble members that differ only in the initial condition of the atmospheric models (i.e., sensitivity of climate model simulations on initial condition). We first quantified the uncertainty related to the internal variability by taking the standard deviation of these five ensemble member for each model. Second, we quantified the intermodel variability by taking the standard deviation of 8 models after averaging first the ensemble members in each model. The results are shown in Figure 3.

Result indicates that there is larger intermodel variability than intramodel variability for zonal, meridional, and wind speed climatology. While intermodel variability signifies model response uncertainty (structural uncertainty), the intramodel variability is related to uncertainty in the initial conditions. The intermodel variability increases from the surface upwards, reaching maximum at the lower stratosphere 


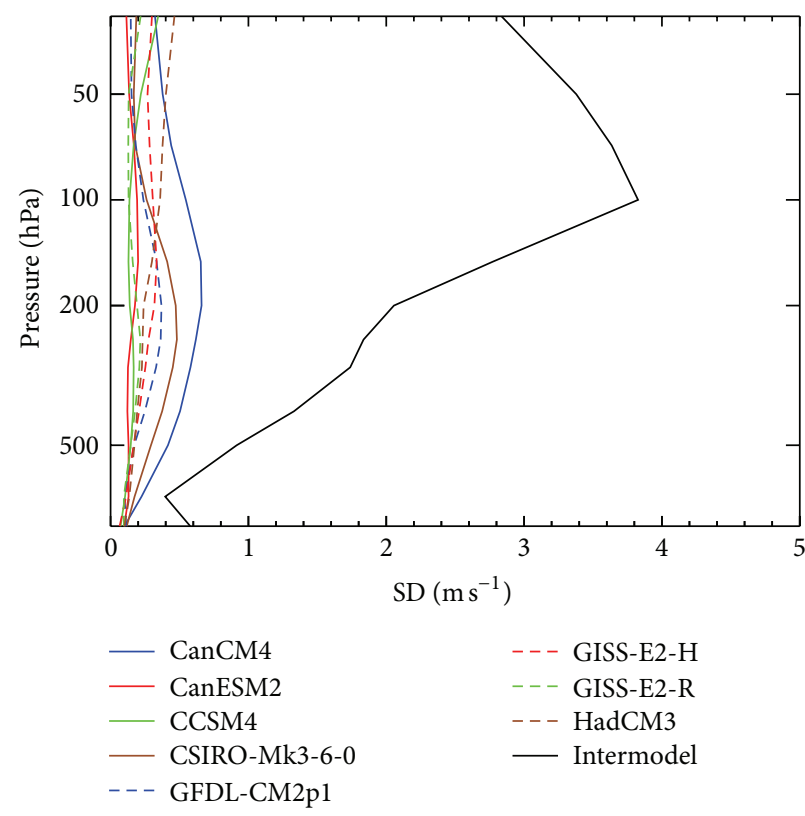

(a) Zonal wind

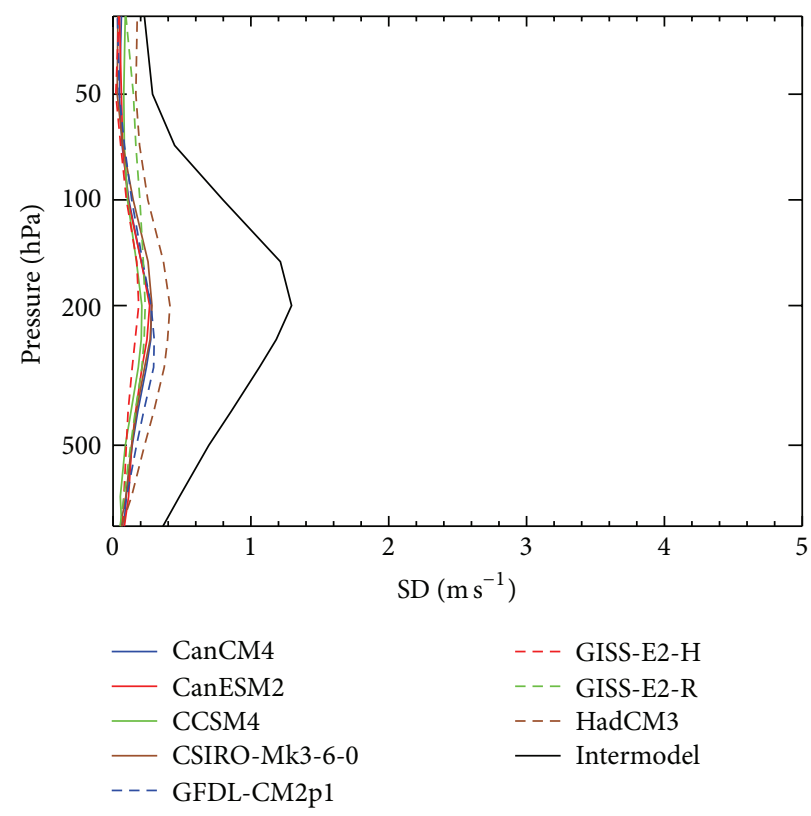

(b) Meridional wind

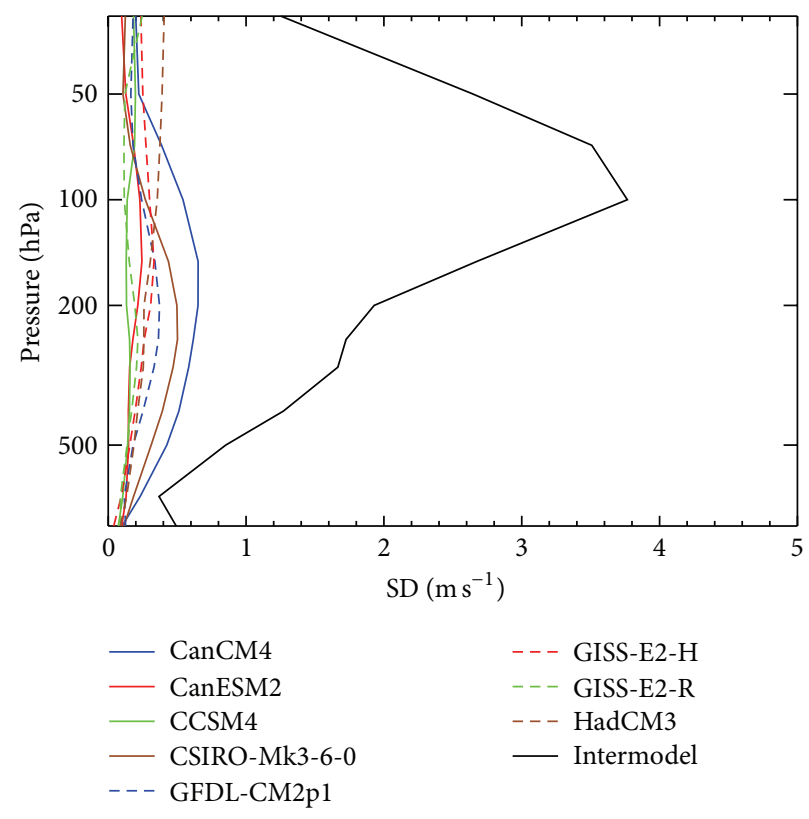

(c) Wind speed

FIGURE 3: Intramodel and intermodal variability for eight models with at least 5 ensemble members.

for zonal wind and wind speed climatology (Figures 3(a) and $3(\mathrm{c})$ ). On the other hand, the variability for meridional wind is much smaller with maximum at the upper troposphere (Figure 3(b)).

Having demonstrated some inherent problems associated with both the use of model, reanalysis, and observation data in climate applications and analysis, we caution that users should thus be aware of these uncertainties. The results based on first ensemble member for each model will be presented in next section.

\section{Results and Discussion}

3.1. Annual Mean Wind Climatology Comparison. Figure 4 shows a vertical profile of the annual mean wind fields from the CMIP5 models, reanalysis, and radiosonde at Sterling, Virginia National Weather station. In addition, both CMIP5 models and reanalysis wind field bias with respect to radiosonde observation are shown (Figures 4(d), $4(\mathrm{e})$, and $4(\mathrm{f}))$. The wind field profiles range from $850 \mathrm{hPa}$ to $30 \mathrm{hPa}$ pressure levels and are annually averaged over 


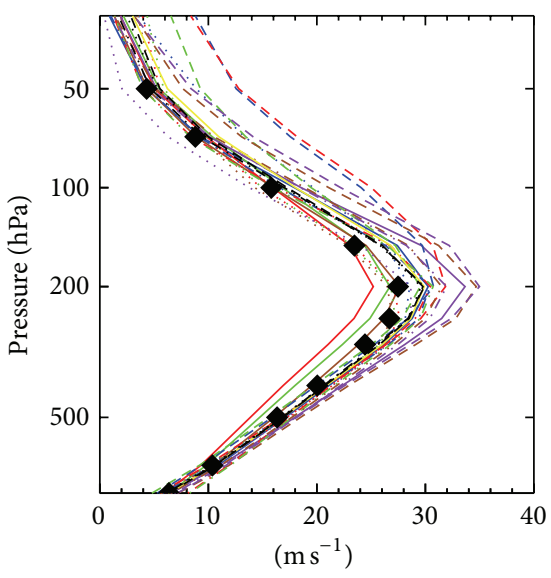

(a) Zonal wind

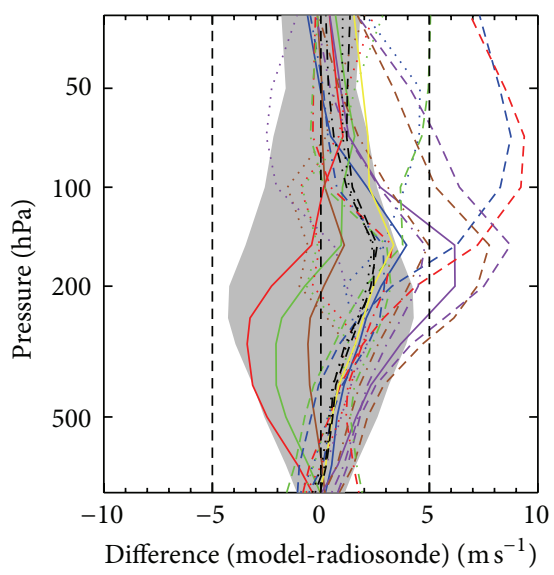

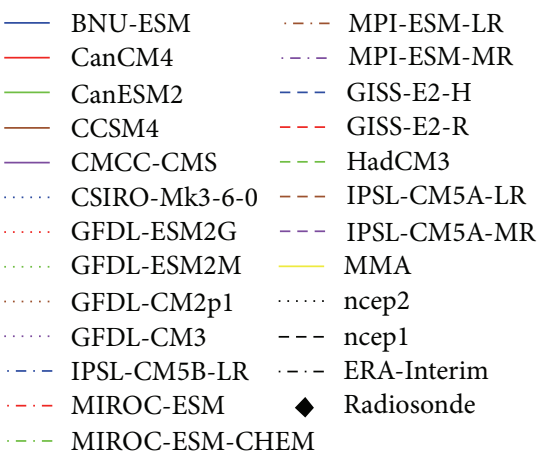

(d) Zonal wind

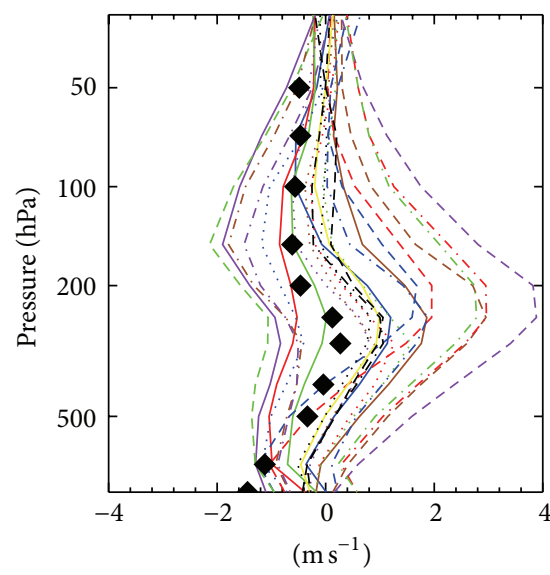

(b) Meridional wind
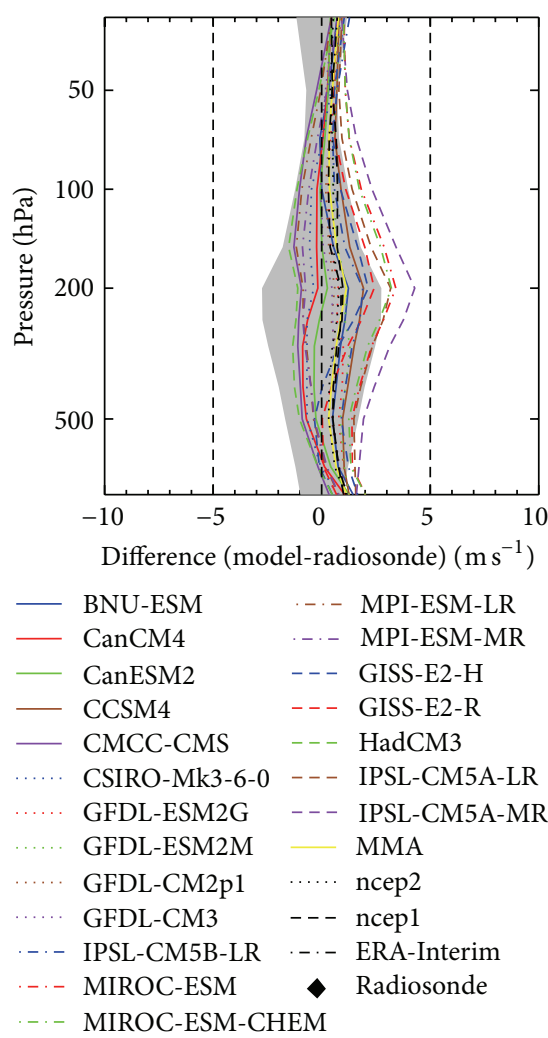

(e) Meridional wind

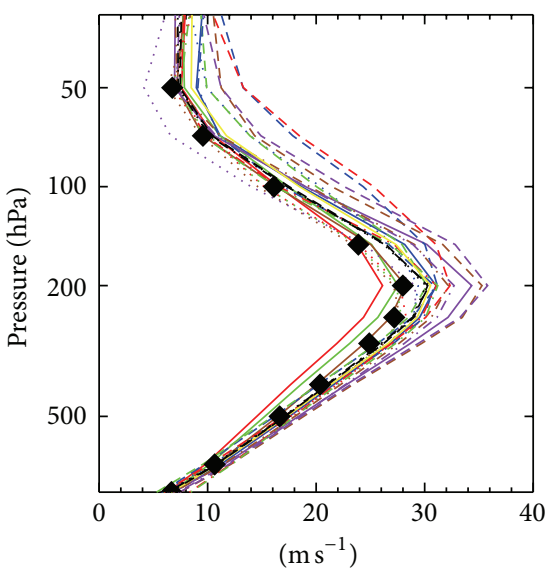

(c) Wind speed

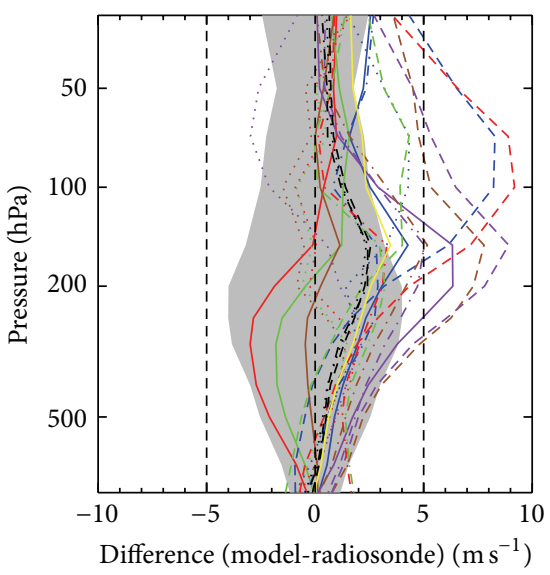

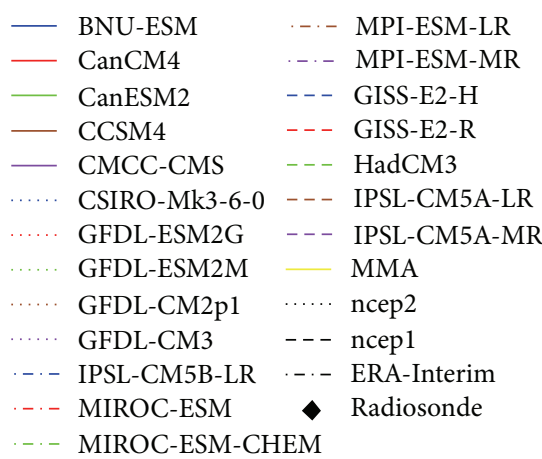

(f) Wind speed

Figure 4: Annual mean climatology (a, b, and c) and climatology difference (bias) relative to radiosonde observation (d, e, and f). The period of study is 1979-2005 from $850 \mathrm{hPa}$ to $30 \mathrm{hPa}$ pressure levels. The radiosonde plus and minus 2 standard deviations around the climatology mean is displayed as the gray shading in the bias plot (d, e, and $\mathrm{f}$ ).

the period 1979-2005. The vertical profiles of zonal and wind speed are very similar (Figures 4(a) and 4(c)) because the magnitudes of meridional wind are $60-70 \%$ smaller than zonal wind (Figure $4(\mathrm{~b})$ ).

Overall, there are reasonable agreements in the shape of the vertical profiles of zonal wind and wind speed among CMIP5, reanalysis, and radiosonde observation, with slight difference in their magnitude. In the troposphere (850$250 \mathrm{hPa}$ ), CMIP5 models agree reasonably well with each other and are generally within $1-8 \mathrm{~m} \mathrm{~s}^{-1}$ of the radiosonde observation, while in stratosphere $(150-30 \mathrm{hPa})$, the spread among the models and the model bias compared to radiosonde increased. For example, at $700 \mathrm{hPa}$, the range of CMIP5 models differs by $\sim 2.8 \mathrm{~m} \mathrm{~s}^{-1}$, and model-to-model variability is $\sim 0.9 \mathrm{~m} \mathrm{~s}^{-1}$ while at $100 \mathrm{hPa}$, the models differ by $\sim 11 \mathrm{~m} \mathrm{~s}^{-1}$ and model-to-model variability is $\sim 3.2 \mathrm{~m} \mathrm{~s}^{-1}$. The increased model-to-model variability is in agreement with the result of quantified uncertainty in the upper troposphere and stratosphere discussed in Section 2.4. The models generally show divergent zonal and wind speed bias that 
ranges from $-5 \mathrm{~m} \mathrm{~s}^{-1}$ to $5 \mathrm{~m} \mathrm{~s}^{-1}$ and majority of the models' bias lies within the 2-sigma radiosonde uncertainty with the exception of the five models (GISS-E2-R, GISS-E2-H, IPSLCM5A-LR, IPSL-CM5A-MR, and HadCM3 models), which overestimated the observed zonal wind by $\sim 5-9 \mathrm{~m} \mathrm{~s}^{-1}$ at the $100 \mathrm{hPa}$ level (Figures 4(d) and 4(f)). Multimodel mean shows better agreement with radiosonde observation.

For the meridional wind (Figure 4(b)), there are disagreements in the magnitude of the vertical profiles among individual CMIP5 models, as well as among CMIP5 models, reanalysis, and radiosonde observation. For example, only small subsets of models (7 out of 20) show negative meridional winds at the upper troposphere. On the other hand, the annual mean climatology of meridional wind from radiosonde is negative for the entire vertical profile, except in the upper troposphere. From $850 \mathrm{hPa}$ to midtroposphere, the magnitude of meridional wind progresses from negative to positive values for 6 out of 20 models as well as the three reanalyses and multimodel mean. The meridional wind bias ranges from $-2 \mathrm{~ms}^{-1}$ to $4 \mathrm{~m} \mathrm{~s}^{-1}$ (Figure $4(\mathrm{e})$ ). The majority of the models' bias is within the radiosonde uncertainty, with only 4 out of 20 models overestimating the meridional wind. Multimodel mean again shows better agreement with radiosonde observation.

3.2. Seasonal Mean Wind Climatology Comparison. The performances of CMIP5 models in their ability to simulate the seasonal climatology are also analyzed. First, the seasonal wind fields of vertical distribution from CMIP5 models, reanalysis, and radiosonde observation are computed by averaging three months (i.e., for December through February (DJF), March through May (MAM), June through August (JJA), and September through November (SON)). Overall, there is agreement in shape of the seasonal horizontal wind and wind speed vertical distribution among CMIP5 models, reanalysis, and radiosonde observation (not shown). Similar to the annual mean climatology, they show an increase in wind fields with height from 850 to $\sim 200 \mathrm{hPa}$ and then wind fields start to decrease with height till $30 \mathrm{hPa}$. The CMIP5 models and reanalysis capture the observed seasonal mean wind vertical distribution with stronger (weaker) wind during the DJF (JJA) season (not shown). Although CMIP5 models and reanalysis capture the phase of the seasonal cycle, the amplitude of the seasonal cycle differs among models. For reanalysis, the maximum difference in the amplitude of the seasonal cycle is located at $\sim 200 \mathrm{hPa}$. In general, CMIP5 and reanalysis bias with respect to radiosonde range from $-10 \mathrm{~m} \mathrm{~s}^{-1}$ to $15 \mathrm{~m} \mathrm{~s}^{-1}$ throughout the vertical profile.

To describe the differences in the climatology of the horizontal wind and wind speed, we will focus on this pressure level $(200 \mathrm{hPa})$. As stated above, CMIP5 and reanalysis capture the phase of the seasonal cycle with stronger (weaker) wind during winter (summer) months (Figures 5(a), 5(c), and 5(e)). This may be associated with stronger (weaker) temperature gradient during winter (summer) months according to thermal wind balance equation. However, difference in the amplitude of the seasonal cycle can be seen between radiosonde and both CMIP5 models and reanalysis, especially for meridional wind.

In addition, while there is variation in the amplitude of the seasonal cycle among individual CMIP5, there is reasonable agreement in amplitude of the seasonal cycle wind fields among the three reanalysis datasets. For zonal wind and wind speed, CMIP5 model bias ranges from -5 to $10 \mathrm{~m} \mathrm{~s}^{-1}$ while reanalysis bias ranges from 0 to $5 \mathrm{~m} \mathrm{~s}^{-1}$ (Figures 5(b) and 5(f)). The three reanalyses, however, overestimated the meridional wind climatology by $\sim 1 \mathrm{~m} \mathrm{~s}^{-1}$ (Figure 5(d)). Most CMIP5 models and reanalysis agree well with observations and lie within one standard deviation of radiosonde observation (Figures 5(b), 5(d) and 5(f)).

3.3. Interannual Variability. Figure 6 shows the interannual variability of wind fields from CMIP5 models, reanalysis products, and radiosonde observations at sterling station for 1979-2005. The variability is evaluated by computing the standard deviation from the yearly annual mean winds. For zonal wind (Figure 6(a)) near the surface $(850 \mathrm{hPa})$, models (16 out of 20 ) overestimated the observed interannual variability while at higher altitude especially in the upper troposphere (200-300 hPa), models (15 out of 20) underestimated the observed interannual variability.

While the vertical interannual variability profile (distribution) of meridional wind and wind speed shows similar profile with zonal wind, the magnitude of maximum interannual variability differs (Figures 6(a), 6(b), and 6(c)). The maximum interannual variability is located at $\sim 200 \mathrm{hPa}$ where radiosonde observations show an interannual variability of $\sim 2.1 \mathrm{~m} \cdot \mathrm{s}^{-1}$ and models show an interannual variability that ranges from $1.6 \mathrm{~m} \cdot \mathrm{s}^{-1}$ (GFDL-ESM2G) to $2.8 \mathrm{~m} \cdot \mathrm{s}^{-1}$ (IPSLCM5B-LR) for zonal and wind speed fields (Figures 6(a) and $6(c))$. On the other hand, the three reanalyses show an interannual variability of $\sim 1.9 \mathrm{~m} \cdot \mathrm{s}^{-1}$. In the case of meridional wind (Figure 6(b)), while radiosonde observations show maximum interannual variability at the jet core by about $1.4 \mathrm{~m} \cdot \mathrm{s}^{-1}$, models have maximum interannual variability that ranges from $1 \mathrm{~m} \cdot \mathrm{s}^{-1}$ (HadCM3) to $2 \mathrm{~m} \cdot \mathrm{s}^{-1}$ (CMCC-CMS).

Also, radiosonde observations, reanalysis, and CMIP5 model show larger interannual variability in the upper troposphere for the three wind fields compared to the lower troposphere. The zonal wind bias (Figure 6(d)) shows that the models generally overestimated the variability above $50 \mathrm{hPa}$, while meridional wind and wind speed are underestimated by the models (Figures 6(e) and 6(f)).

3.4. Annual Wind Trends. In Figure 7, the CMIP5 model and reanalysis trends are compared to the radiosonde trends from $850 \mathrm{hPa}$ to $30 \mathrm{hPa}$ for the three wind fields. As noted above (Figure 2), first two nearby grid cells for individual CMIP5 models and reanalysis dataset are chosen as a climatic representative of Sterling radiosonde station as shown in Figure 1(a). Then the CMIP5 model and reanalysis trends are calculated from the averaged two nearby grid cells around the radiosonde observations. The trends from radiosonde at each vertical level are calculated using a least square linear 


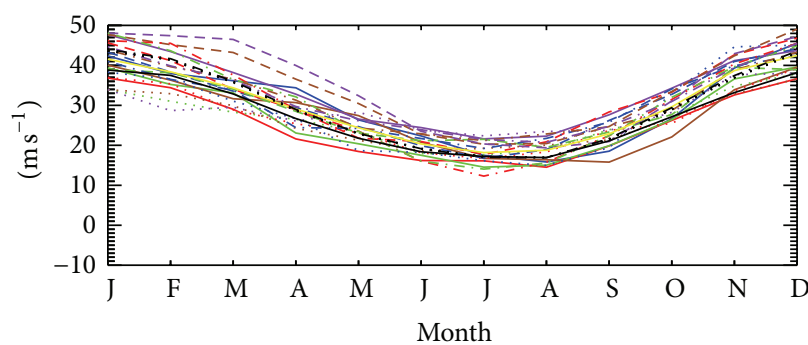

(a) Zonal wind

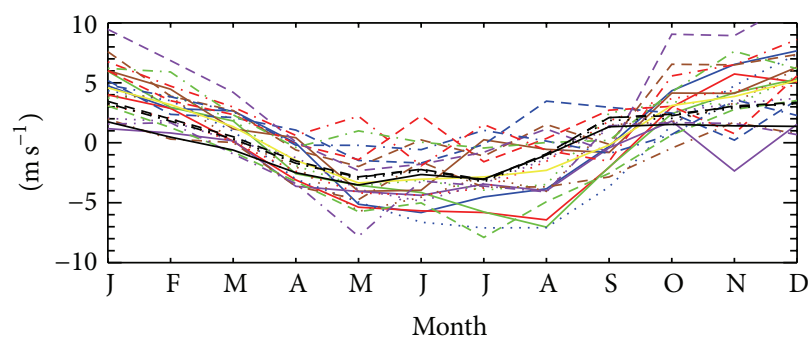

(c) Meridional wind

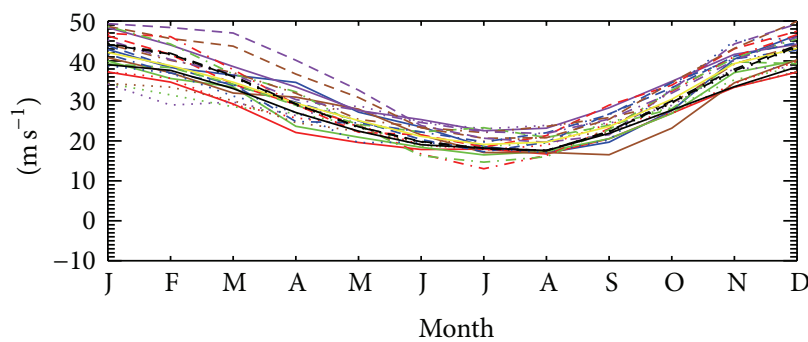

$\begin{array}{ll}- & \text { BNU-ESM } \\ - & \text { CanCM4 } \\ - & \text { CanESM2 } \\ - & \text { CCSM4 } \\ - & \text { CMCC-CMS } \\ \ldots \ldots & \text { CSIRO-Mk3-6-0 } \\ \ldots \ldots & \text { GFDL-ESM2G } \\ \ldots \ldots & \text { GFDL-ESM2M } \\ \ldots \ldots & \text { GFDL-CM2p1 } \\ \ldots \ldots & \text { GFDL-CM3 } \\ \ldots- & \text { IPSL-CM5B-LR } \\ \ldots & \text { MIROC-ESM } \\ \ldots- & \text { MIROC-ESM-CHEM }\end{array}$

(e) Wind speed

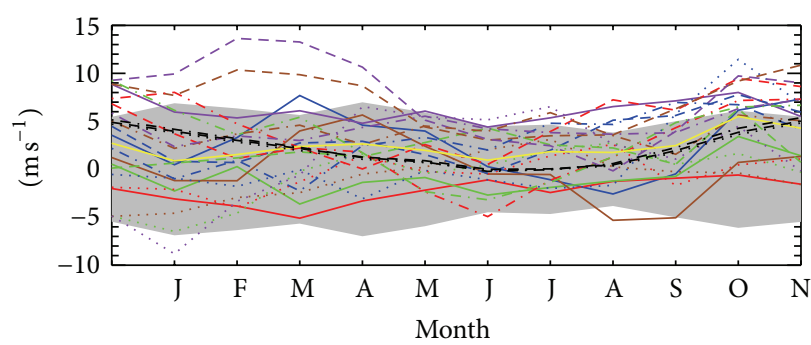

(b) Zonal wind bias

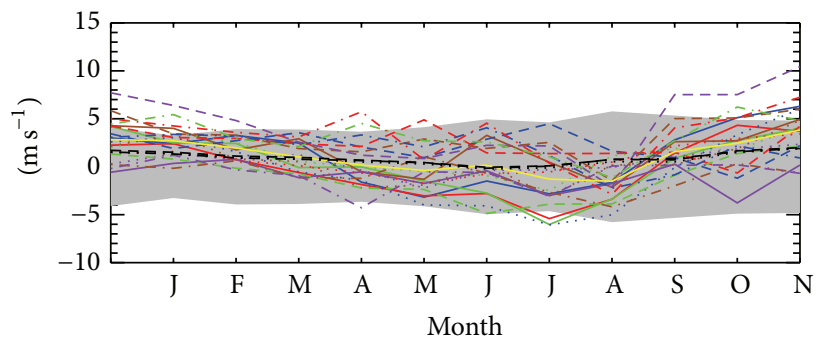

(d) Meridional wind bias
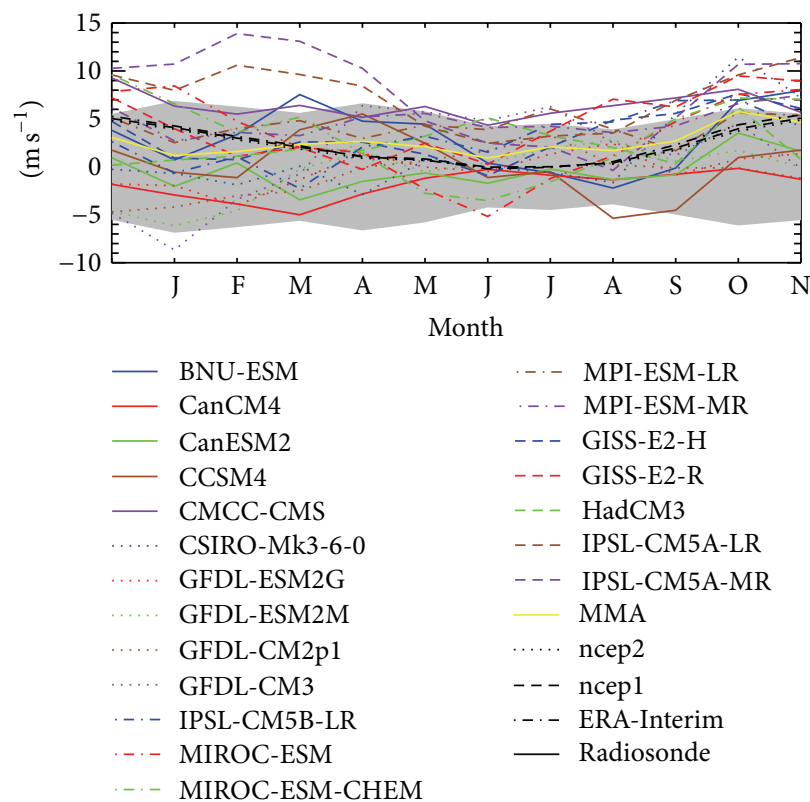

(f) Wind speed bias

FIGURE 5: Sterling station seasonal cycle at $200 \mathrm{hPa}$ from individual CMIP5, reanalysis, and radiosonde observation for 1979-2005. The gray shading in (b), (d), and (f) is the radiosonde plus and minus 1 standard deviation around the climatology mean.

regression after monthly means of zonal and meridional wind at $00 \mathrm{Z}$ and $12 \mathrm{Z}$ are averaged.

In general, there is similarity in the shape and magnitude of the vertical zonal wind and wind speed trend profile. The shape of meridional wind trend profile differs slightly from both zonal wind and wind speed. Besides, the magnitude meridional wind trend profile is small. Overall, radiosonde observation shows positive trends from $850 \mathrm{hPa}$ to $50 \mathrm{hPa}$ for zonal wind and wind speed. Further information about the observed trends can also be found by examining the 2-sigma (95\%) confidence interval in the observations. The trend confidence interval in zonal, meridional, and wind speed is about twice as large in upper troposphere and lower stratosphere (i.e., at pressure levels between $300 \mathrm{hPa}$ and $100 \mathrm{hPa}$ ) compared to the lower troposphere (i.e., at pressure level between $850 \mathrm{hPa}$ and $300 \mathrm{hPa}$ ). For example, zonal wind annual mean trend confidence interval at $200 \mathrm{hPa}$ is $0.9 \mathrm{~m} \mathrm{~s}^{-1}$ decade $^{-1}$ whereas at $500 \mathrm{hPa}$, it is about $0.46 \mathrm{~m} \mathrm{~s}^{-1} \mathrm{decade}^{-1}$. This larger confidence interval in upper troposphere and lower stratosphere (UTLS) indicates that the upper troposphere and lower stratosphere are subjected to larger variability than the troposphere (Figures 6(a), 6(b), and 6(c)). The larger confidence interval in UTLS from the observation might be associated with either larger radiosonde uncertainty or variability of the jet stream or combination of observational uncertainty and variability of the jet stream [24]. 


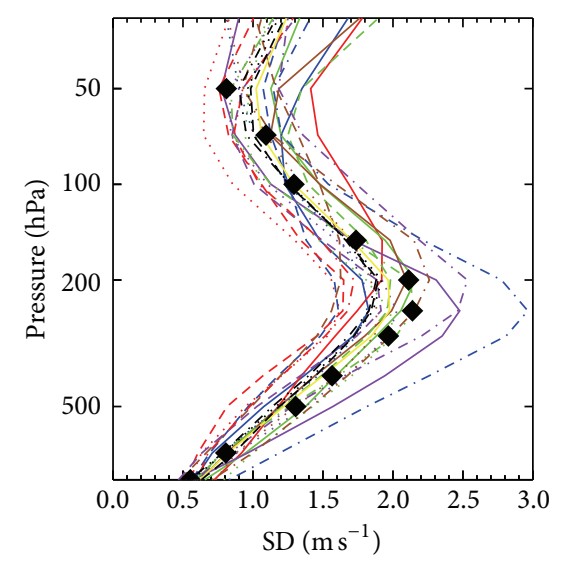

(a) Zonal wind
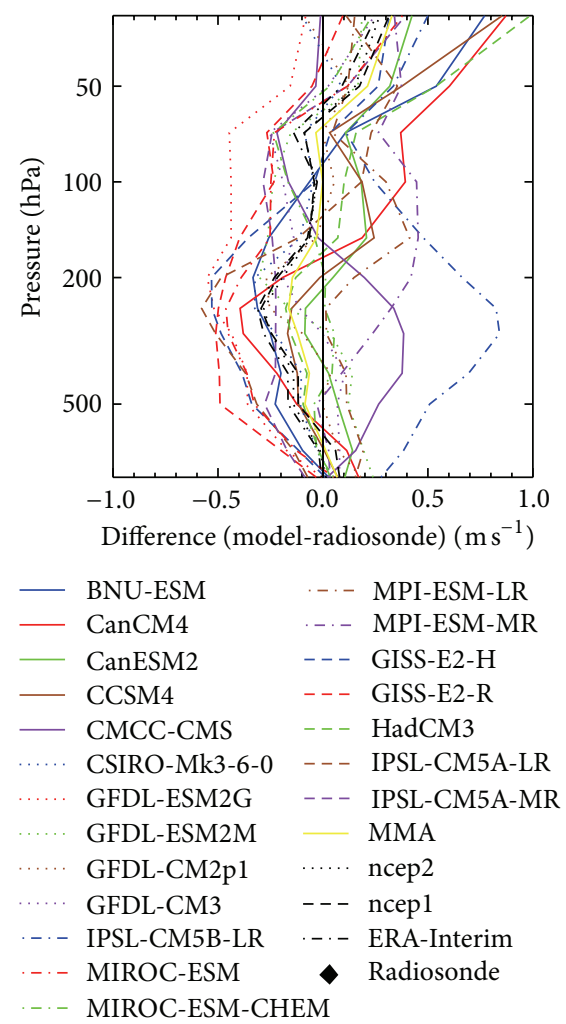

(d) Zonal wind

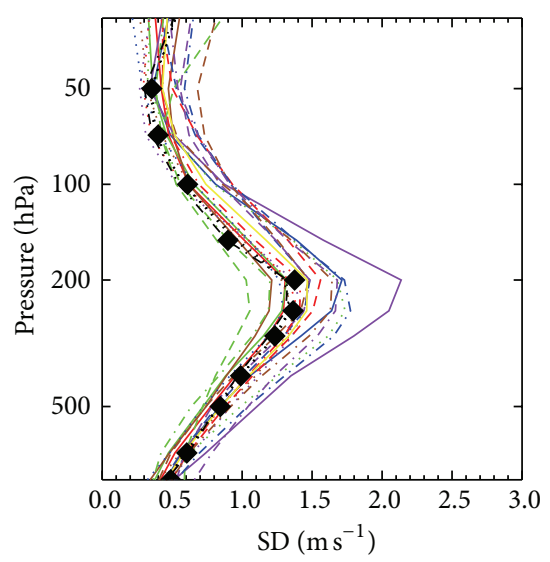

(b) Meridional wind
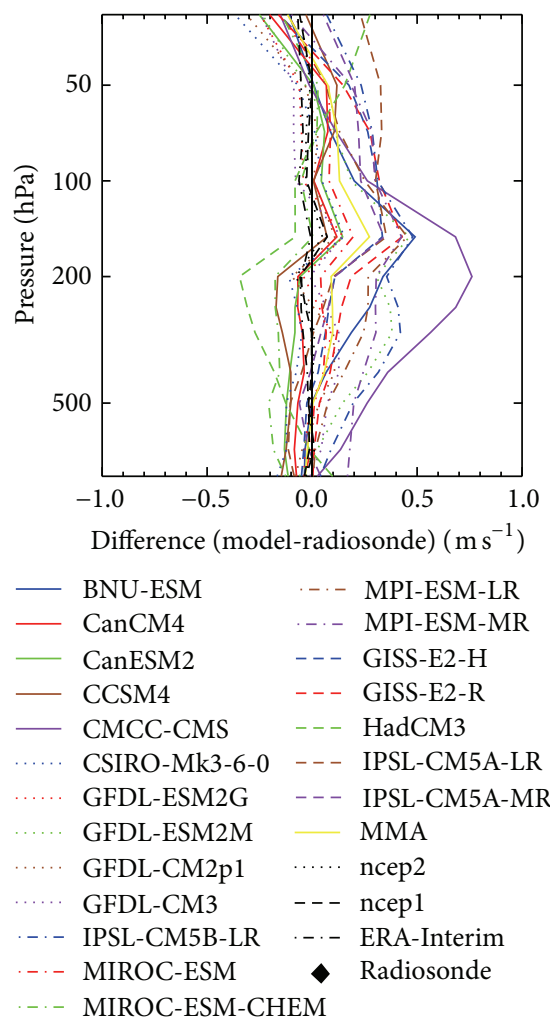

(e) Meridional wind

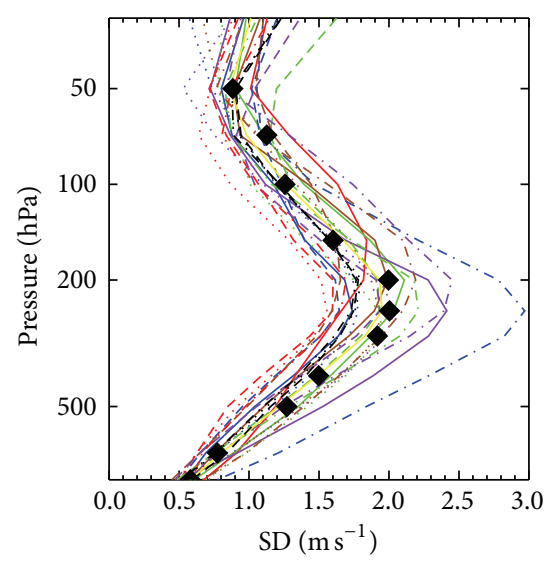

(c) Wind speed

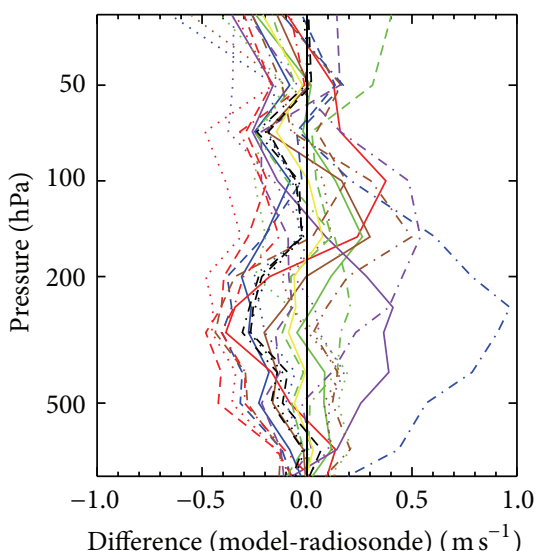

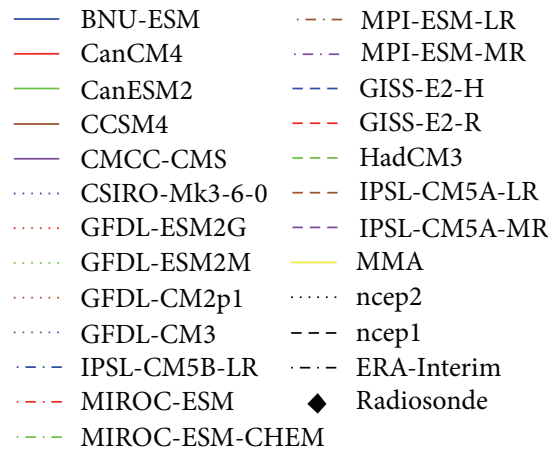

(f) Wind speed

FiguRE 6: Similar to Figure 4 but for comparison of radiosonde, reanalysis, and CMIP5 model wind fields interannual variability (a, b, and c) and bias with respect to radiosonde (d, e, and f). Data is from 1979 to 2005.

Out of the 20 CMIP5 models, seven (7) show positive zonal wind and wind speed trends (Figures $7(\mathrm{a})$ and $7(\mathrm{c})$ ). For reanalysis, there are negative zonal wind and wind speed trends in the lower troposphere (below $400 \mathrm{hPa}$ ). Furthermore, reanalysis shows positive zonal wind and wind speed trends from $400-100 \mathrm{hPa}$. Overall, the trends from CMIP5, reanalysis, and radiosonde observations are not statistically significant at $95 \%$ confidence levels at each pressure level which may be related to the high interannual variability of the wind dataset and shorter period of analysis.

So far the analysis was based on output from historical simulations for the period from 1979 to 2005. The result generally indicates that any climate change trend in the 27 years of observed and simulated wind is not yet distinguishable from the natural interannual to decadal variability using a single point observation. Next section deals with the number of years required to detect statistically significant trends from radiosonde observation.

\section{Wind Trend Detection from Observation}

In this section, we addressed the question of the number of years required to detect statistically significant wind trends with the probability of 0.9 from Sterling radiosonde 


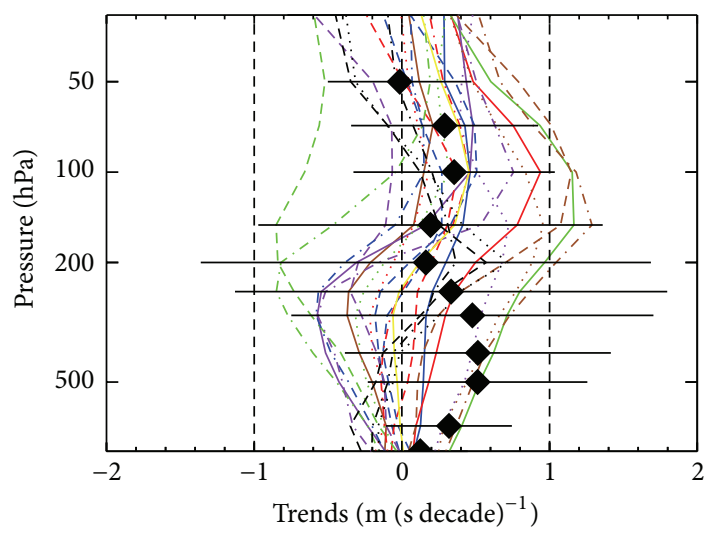

(a) Zonal wind

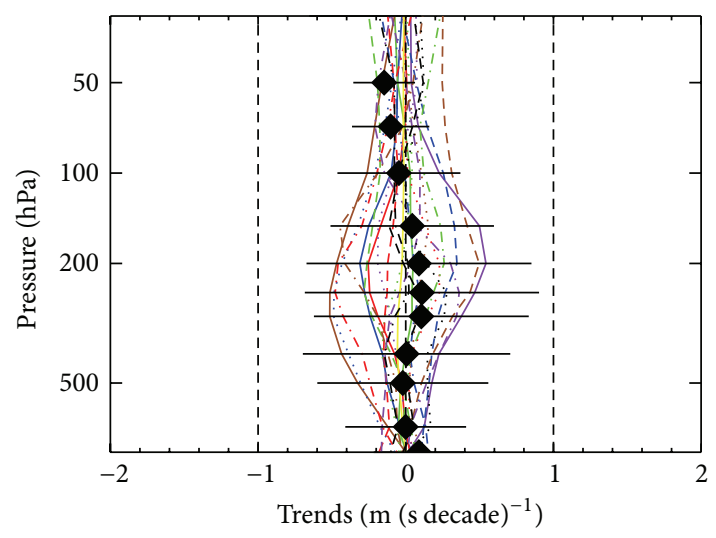

(b) Meridional wind

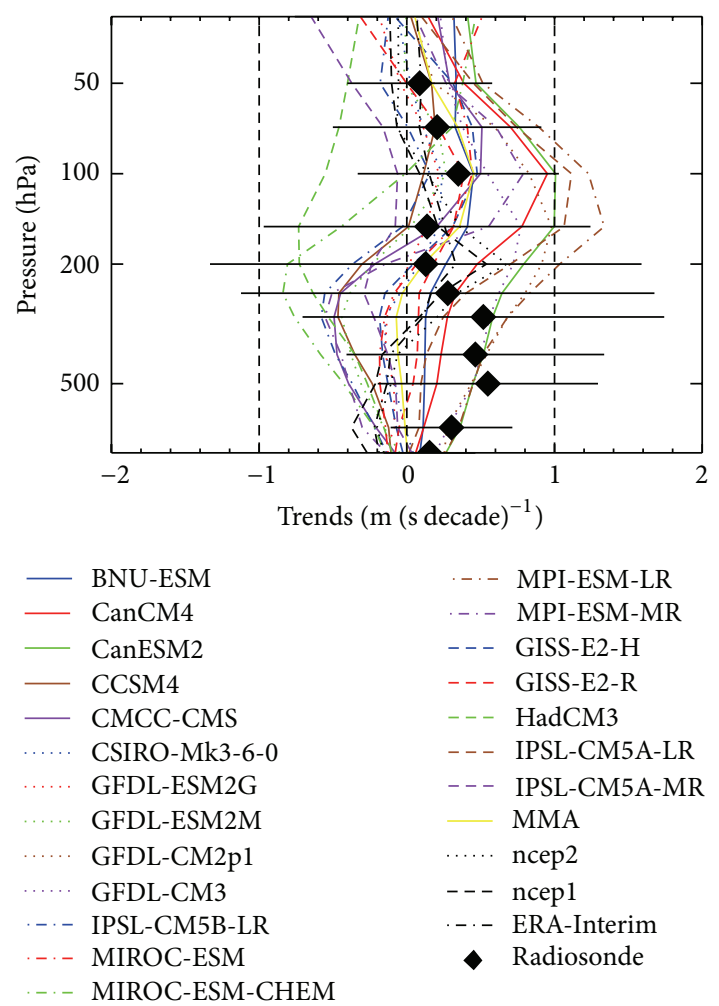

(c) Wind speed

FIGURE 7: The vertical distributions of annual mean horizontal wind and wind speed trends from radiosonde, reanalysis, and CMIP5 models calculated for 1979-2005. Horizontal black line represents the 2-sigma variation in wind.

observation (see (1) and [28] for detailed discussion). The three parameters required to evaluate the number of years of wind speed data needed to detect statistically significant wind trends are the magnitude of expected trend, standard deviation, autocorrelation of the wind speed noise. These three parameters vary according to location and altitude [37].

In this study, ensemble mean zonal, meridional, and wind speed trends from CSIRO-MK3.6.0 model for the period 2016-2050 are used as example for estimation of future trends. The ensemble mean trends are evaluated by averaging the individual 10 run trends found from CSIRO-MK3.6.0 model. The ensemble mean trends and uncertainty in the mean trends for the three wind fields are plotted in Figure 9.
First, the model generally shows similar vertical profile of zonal wind and wind speed trends (Figures 9(a) and 9(e)), with decreasing trend in the troposphere and increasing trend in the stratosphere. For meridional wind, model shows an increasing trend, with maximum increasing trend occurring at $\sim 200 \mathrm{hPa}$ (Figure 9(c)). Also, there is variation in the trend estimated from the individual ensemble members as indicated by the one standard deviation uncertainty error bar. This indicates the uncertainty in model estimated trends associated with uncertainty in initial condition.

The standard deviation and autocorrelation of the horizontal wind as well as wind speed noise are estimated from Sterling radiosonde observation wind field time series for 


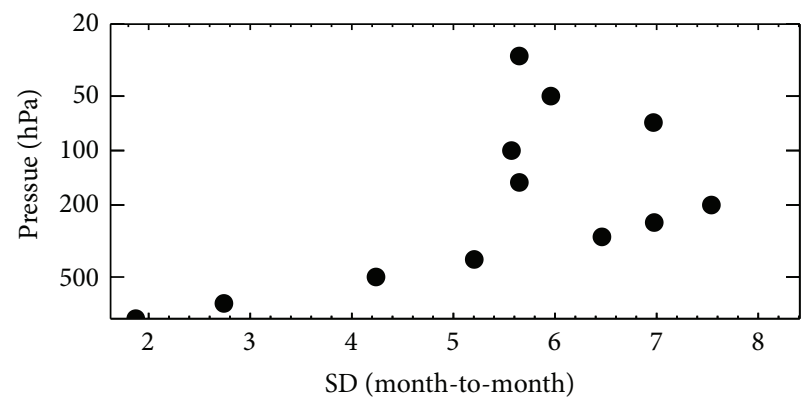

(a) Zonal wind variability

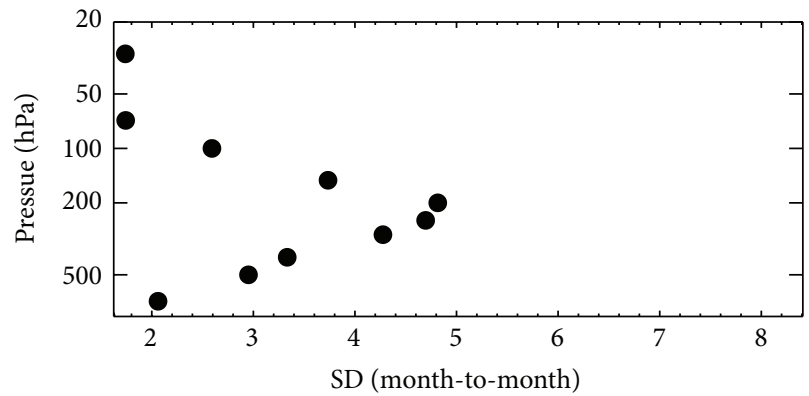

(c) Meridional wind variability

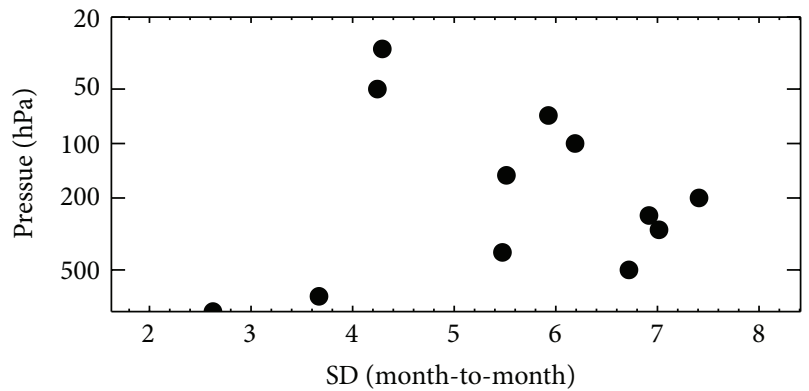

(e) Wind speed variability

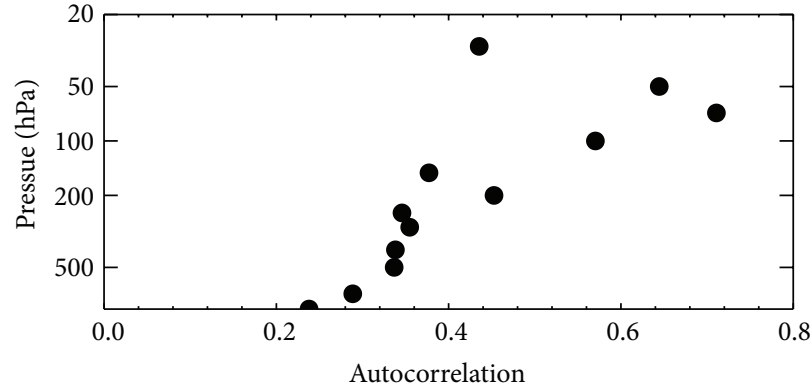

(b) Zonal wind autocorrelation

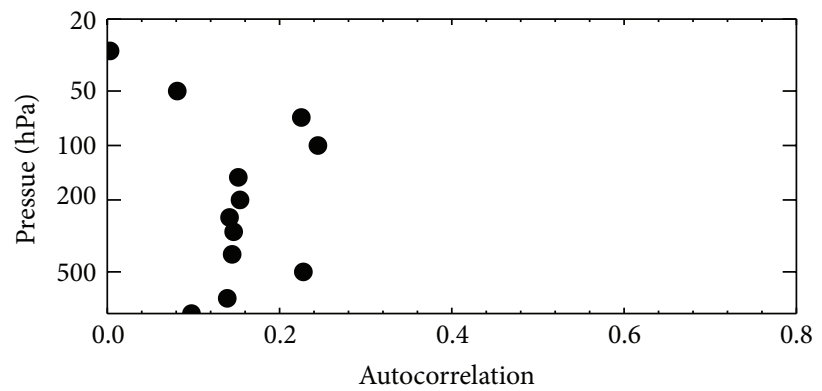

(d) Meridional wind autocorrelation

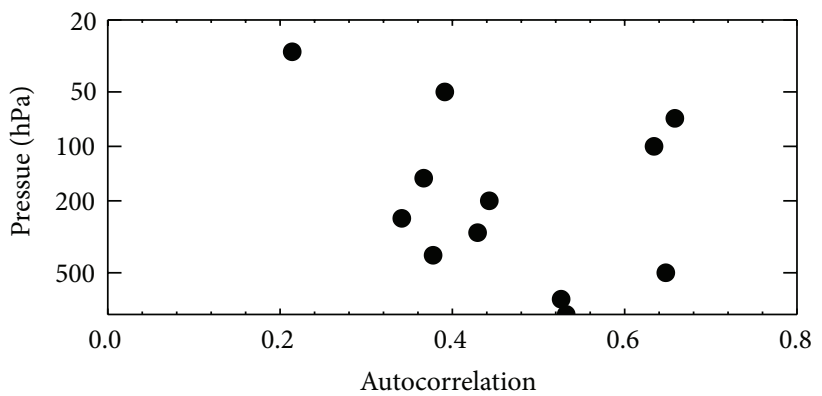

(f) Wind speed autocorrelation

Figure 8: Month-to-month variability and autocorrelation for zonal wind (a, b), meridional wind (c, d), and wind speed (e, f), respectively. The observational data was from 1979 to 2012 for Sterling station Virginia Station.

the period 1979-2012 after rearranging (2) for wind field noise. Figure 8 shows month-to-month variability and autocorrelation of horizontal wind and wind speed data. There is similarity in the shape of the vertical profile of month-to-month variability derived from horizontal wind and wind speed monthly data (Figures 8(a), 8(b), and 8(c)). Their month-to-month variability generally increases with height, with maximum variability occurring around $200 \mathrm{hPa}$ and thereafter the variability decreases with height. With respect to month-to-month autocorrelation, zonal wind shows an increase of month-to-month autocorrelation with height, while meridional wind shows almost constant month-to-month autocorrelation especially at pressure levels between $500 \mathrm{hPa}$ and $150 \mathrm{hPa}$ (Figures 8(b) and 8(d)). Wind speed data show divergent month-to-month autocorrelation (Figure 8(f)).

Radiosonde wind observation data from 1979 to 2012 are used to estimate month-to-month variability and autocorrelation in wind field dataset. Assuming these two parameters would remain the same in the future and the ensemble mean trends estimated from CSIRO-MK3.6.0 are accurate (Figures 9(a), 9(c), and 9(e)), the number of years needed to detect statistically significant trends is evaluated as shown in Figure 9. Result indicates that we will need longer time series of wind data to detect statistically significant trends. For zonal wind and wind speed, we would need approximately 100 to 300 years of data depending on the altitude (Figures 9 (b) and 9(f)). For meridional wind, we would need approximately 70 to 140 years of data (Figure $9(\mathrm{~d})$ ). Thus, meridional wind trends would be detected sooner than zonal and wind speed trends.

Overall, the zonal wind trend mirrors the wind speed trend while the number of years to obtain statistically significant trend decreases with increasing pressure level except for upper troposphere. In the upper troposphere $(\sim 200 \mathrm{hPa})$ for zonal (Figure 9(b)) and wind speed (Figure 9(f)), there is relatively higher number of years needed to detect trend relative to meridional wind (Figure 9(d)). At this level, 


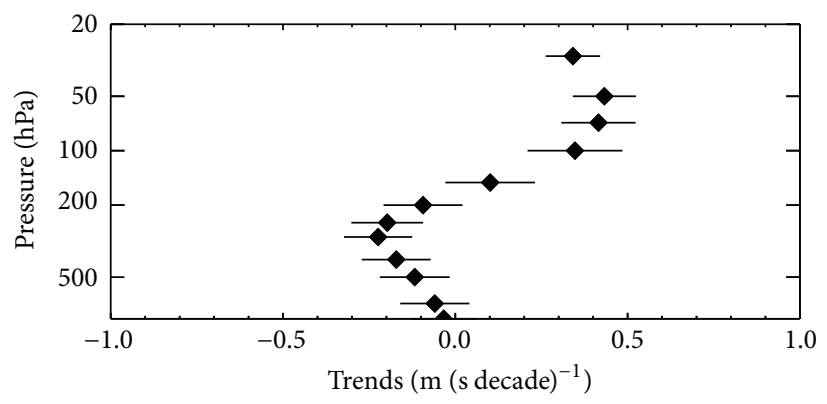

(a) CSIRO-MK360 (2016-2050)

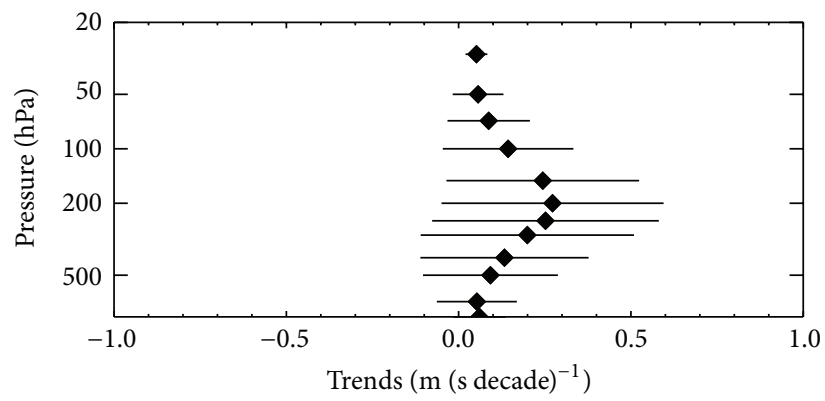

(c) CSIRO-MK360 (2016-2050)

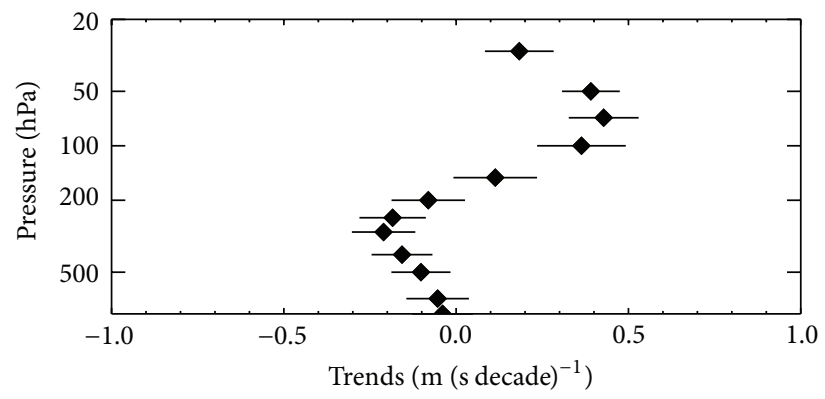

(e) CSIRO-MK360 (2016-2050)

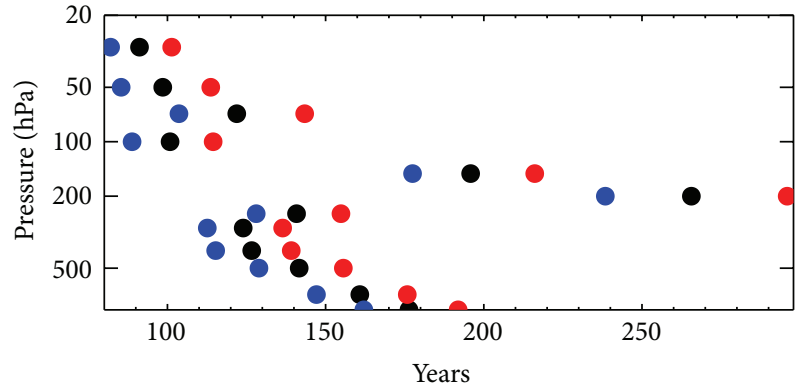

(b) Number of years

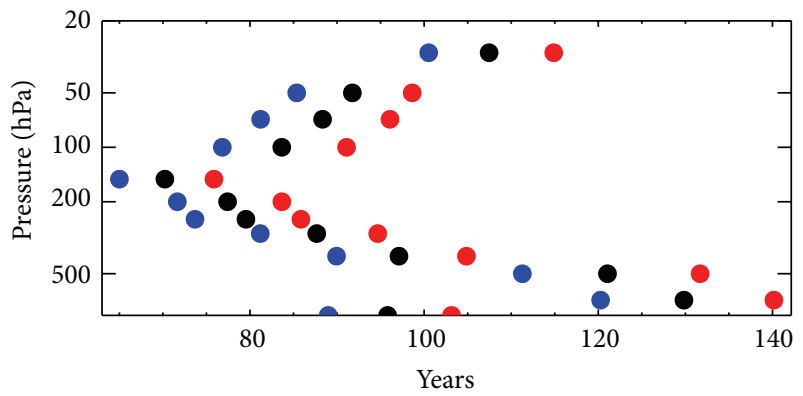

(d) Number of years

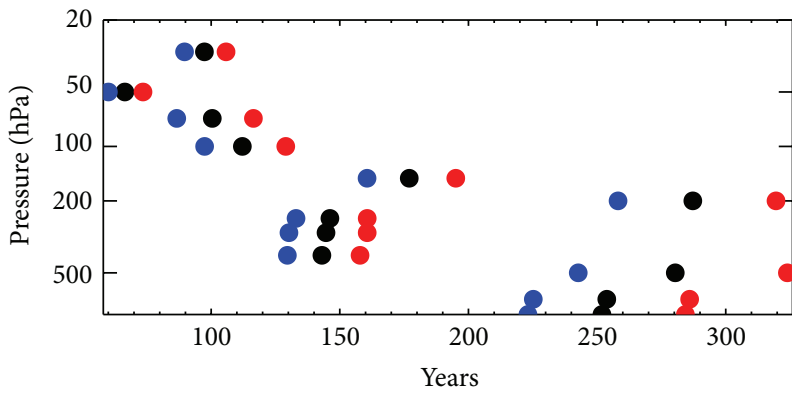

(f) Number of years

FiguRE 9: Future estimated trends and numbers of years for zonal wind ( $a, b)$, meridional wind ( $c, d)$, and wind speed (e, f), respectively. Black diamond symbol represents the ensemble mean trends calculated by averaging trends found from individual 10 ensemble member. Horizontal black thin line in (a), (c), and (e) represents 1-sigma trend uncertainty. Circle symbols represent number of years (black filled circle represents the mean, blue the minimum, and red the maximum). Note that the blue circles and red circles in (b), (d), and (f) represent the $95 \%$ confidence interval for the number of years which is represented by black circle.

the trend magnitude is almost the same (Figures 9(a), 9(c), and $9(\mathrm{e})$ ) but the magnitude of month-to-month variability and autocorrelation varies (Figure 8). Thus, the longer time needed to detect a statistically significant trend for both zonal wind and wind speed relative to meridional wind can be attributed to the higher month-to-month variability and autocorrelation found in both zonal wind and wind speed relative to the meridional wind.

\section{Summary}

In this study, monthly mean wind data from CMIP5 simulations was used to examine models and their ability to represent annual and seasonal historical wind variability and trends from the $850 \mathrm{hPa}$ to $30 \mathrm{hPa}$ pressure level. We then characterized and compared the observed and simulated wind fields (zonal, meridional, and wind speed) with respect to climatology mean, variability, and trends for both annual mean and seasonal mean. We also calculated the number of years needed to detect trend.

We summarize our results as follows:

(1) Overall, zonal wind and wind speed vertical profiles are very similar in terms of shape and magnitude. The vertical profiles of individual CMIP5 models, as well as among CMIP5 models, reanalysis, and radiosonde observation, however, show some disagreement in the sign of the meridional wind magnitude.

(2) Although the CMIP5 models reproduce the observed vertical profile of the annual mean zonal wind climatology reasonably well, there are bias and variability among models, which is larger at the stratosphere (above $\sim 200 \mathrm{hPa}$ ). When reanalyses are compared to radiosonde, their spread among each other and 
bias with respect to radiosonde are smaller. This is expected because the radiosonde observation has already been assimilated into these reanalysis products.

(3) The CMIP5 models and reanalysis capture the observed seasonal cycle throughout the vertical profile, with stronger (weaker) wind during the winter (summer) season. There is, however, variation in the amplitude of the seasonal cycle among models, and reanalysis with maximum difference in the amplitude of the seasonal cycle located $\sim 200 \mathrm{hPa}$.

(4) As expected, it is challenging to find statistically significant trends at local scale due to small signalto-noise ratio. Longer wind time series would be required for the trends to be statistically significant for a single point measurement.

(5) Our analysis shows that intramodel spread is smaller than intermodel variability suggesting that the role of internal variability is negligible. It thus follows that the model response uncertainty is responsible for the disagreement in the vertical profiles of the wind fields.

\section{Conflict of Interests}

The authors declare that there is no conflict of interests regarding the publication of this paper.

\section{References}

[1] J. Sheffield, A. P. Barrett, B. Colle et al., "North American Climate in CMIP5 experiments. Part I. Evaluation of historical simulations of continental and regional climatology," Journal of Climate, vol. 26, no. 23, pp. 9209-9245, 2013.

[2] J. Sheffield, S. J. Camargo, R. Fu et al., "North American climate in CMIP5 experiments. Part II: evaluation of historical simulations of intraseasonal to decadal variability," Journal of Climate, vol. 26, no. 23, pp. 9247-9290, 2013.

[3] T. J. Bracegirdle, E. Shuckburgh, J.-B. Sallee et al., "Assessment of surface winds over the Atlantic, Indian, and Pacific Ocean sectors of the Southern Ocean in CMIP5 models: historical bias, forcing response, and state dependence," Journal of Geophysical Research: Atmospheres, vol. 118, no. 2, pp. 547-562, 2013.

[4] A. K. Betts, M. Zhao, P. A. Dirmeyer, and A. C. M. Beljaars, "Comparison of ERA40 and NCEP/DOE near-surface data sets with other ISLSCP-II data sets," Journal of Geophysical Research, vol. 111, no. 22, Article ID D22S04, 2006.

[5] E. D. Maloney, S. J. Camargo, E. Chang et al., "North American climate in CMIP5 experiments: part III: assessment of twentyfirst-century projections," Journal of Climate, vol. 27, no. 6, pp. 2230-2270, 2014.

[6] Q. Fu, C. M. Johanson, J. M. Wallace, and T. Reichler, "Enhanced mid-latitude tropospheric warming in satellite measurements," Science, vol. 312, no. 5777, p. 1179, 2006.

[7] J. Lu, G. A. Vecchi, and T. Reichler, "Expansion of the Hadley cell under global warming," Geophysical Research Letters, vol. 34, no. 6, Article ID L06805, 2007.

[8] C. M. Johanson and Q. Fu, "Hadley cell widening: model simulations versus observations," Journal of Climate, vol. 22, no. 10, pp. 2713-2725, 2009.
[9] D. J. Seidel, Q. Fu, W. J. Randel, and T. J. Reichler, "Widening of the tropical belt in a changing climate," Nature Geoscience, vol. 1, no. 1, pp. 21-24, 2008.

[10] T. Woollings and M. Blackburn, "The north Atlantic jet stream under climate change and its relation to the NAO and EA patterns," Journal of Climate, vol. 25, no. 3, pp. 886-902, 2012.

[11] C. Ihara and Y. Kushnir, "Change of mean midlatitude westerlies in 21st century climate simulations," Geophysical Research Letters, vol. 36, no. 13, Article ID L13701, 2009.

[12] E. P. Gerber, A. Butler, N. Calvo et al., "Assessing and understanding the impact of stratospheric dynamics and variability on the Earth system," Bulletin of the American Meteorological Society, vol. 93, no. 6, pp. 845-859, 2012.

[13] J. R. Holton, An Introduction to Dynamic Meteorology, vol. 88 of International Geophysics Series, Elsevier Academic Press, Burlington, Mass, USA, 2004.

[14] C. L. Archer and K. Caldeira, "Historical trends in the jet streams," Geophysical Research Letters, vol. 35, no. 8, Article ID L08803, 2008.

[15] R. Vautard, J. Cattiaux, P. Yiou, J.-N. Thépaut, and P. Ciais, "Northern Hemisphere atmospheric stilling partly attributed to an increase in surface roughness," Nature Geoscience, vol. 3, no. 11, pp. 756-761, 2010.

[16] L. B. Hande, S. T. Siems, M. J. Manton, and D. Belusic, "Observations of wind shear over the Southern Ocean," Journal of Geophysical Research, vol. 117, no. 12, p. 12206, 2012.

[17] R. Rüfenacht, A. Murk, N. Kämpfer, P. Eriksson, and S. A. Buehler, "Middle-atmospheric zonal and meridional wind profiles from polar, tropical and midlatitudes with the groundbased microwave Doppler wind radiometer WIRA," Atmospheric Measurement Techniques, vol. 7, no. 12, pp. 4491-4505, 2014.

[18] E. Kalnay, M. Kanamitsu, R. Kistler et al., "The NCEP/NCAR 40-year reanalysis project," Bulletin of the American Meteorological Society, vol. 77, no. 3, pp. 437-471, 1996.

[19] M. Kanamitsu, W. Ebisuzaki, J. Woollen et al., "The NCEP-DOE AMIP-II reanalysis (R-2)," Bulletin of the American Meteorological Society, vol. 83, no. 11, pp. 1631-1643, 2002.

[20] D. P. Dee, S. M. Uppala, A. J. Simmons et al., “The ERA-interim reanalysis: configuration and performance of the data assimilation system," Quarterly Journal of the Royal Meteorological Society, vol. 137, no. 656, pp. 553-597, 2011.

[21] I. Durre, R. S. Vose, and D. B. Wuertz, "Overview of the integrated global radiosonde archive," Journal of Climate, vol. 19, no. 1, pp. 53-68, 2006.

[22] K. E. Taylor, R. J. Stouffer, and G. A. Meehl, "An overview of CMIP5 and the experiment design," Bulletin of the American Meteorological Society, vol. 93, no. 4, pp. 485-498, 2012.

[23] B. D. Santer, C. Mears, C. Doutriaux et al., "Separating signal and noise in atmospheric temperature changes: the importance of timescale," Journal of Geophysical Research, vol. 116, no. 22, Article ID D22105, 2011.

[24] D. J. Seidel, M. Free, and J. S. Wang, "Reexamining the warming in the tropical upper troposphere: models versus radiosonde observations," Geophysical Research Letters, vol. 39, no. 22, Article ID L22701, 2012.

[25] J. M. Arblaster, G. A. Meehl, and D. J. Karoly, "Future climate change in the Southern Hemisphere: competing effects of ozone and greenhouse gases," Geophysical Research Letters, vol. 38, no. 2, Article ID L02701, 2011. 
[26] K. E. Taylor, "Summarizing multiple aspects of model performance in a single diagram," Journal of Geophysical Research, vol. 106, no. 7, Article ID 2000JD900719, pp. 7183-7192, 2001.

[27] B. D. Santer, T. M. L. Wigley, J. S. Boyle et al., "Statistical significance of trends and trend differences in layer-average atmospheric temperature time series," Journal of Geophysical Research, vol. 105, no. 6, pp. 7337-7356, 2000.

[28] E. C. Weatherhead, G. C. Reinsel, G. C. Tiao et al., "Factors affecting the detection of trends: statistical considerations and applications to environmental data," Journal of Geophysical Research: Atmospheres, vol. 103, no. 14, pp. 17149-17161, 1998.

[29] D. N. Whiteman, K. C. Vermeesch, L. D. Oman, and E. C. Weatherhead, "The relative importance of random error and observation frequency in detecting trends in upper tropospheric water vapor," Journal of Geophysical Research, vol. 116, no. 21, Article ID D21118, 2011.

[30] T. Reichler and J. Kim, "Uncertainties in the climate mean state of global observations, reanalyses, and the GFDL climate model," Journal of Geophysical Research: Atmospheres, vol. 113, no. 5, pp. 1984-2012, 2008.

[31] G. A. Meehl, J. M. Arblaster, and C. Tebaldi, "Understanding future patterns of increased precipitation intensity in climate model simulations," Geophysical Research Letters, vol. 32, no. 18, Article ID L18719, 4 pages, 2005.

[32] D. A. Stainforth, M. R. Allen, E. R. Tredger, and L. A. Smith, "Confidence, uncertainty and decision-support relevance in climate predictions," Philosophical Transactions of the Royal Society A, vol. 365, no. 1857, pp. 2145-2161, 2007.

[33] S. M. Uppala, P. W. Kallberg, A. J. Simmons et al., "The ERA40 reanalysis," Quarterly Journal of the Royal Meteorological Society, vol. 131, no. 612, pp. 2961-3012, 2005.

[34] L. Bengtsson, S. Hagemann, and K. I. Hodges, "Can climate trends be calculated from reanalysis data?" Journal of Geophysical Research, vol. 109, no. 11, Article ID D11111, 2004.

[35] G. J. Marshall, "Trends in Antarctic geopotential height and temperature: a comparison between radiosonde and NCEPNCAR reanalysis data," Journal of Climate, vol. 15, no. 6, pp. 659-674, 2002.

[36] A. Sterl, "On the (in)homogeneity of reanalysis products," Journal of Climate, vol. 17, no. 19, pp. 3866-3873, 2004.

[37] E. C. Weatherhead, A. J. Stevermer, and B. E. Schwartz, "Detecting environmental changes and trends," Physics and Chemistry of the Earth, vol. 27, no. 6-8, pp. 399-403, 2002. 

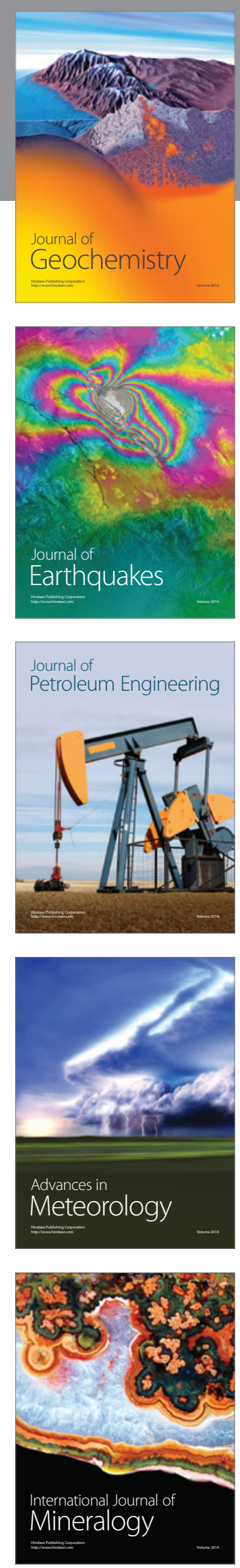
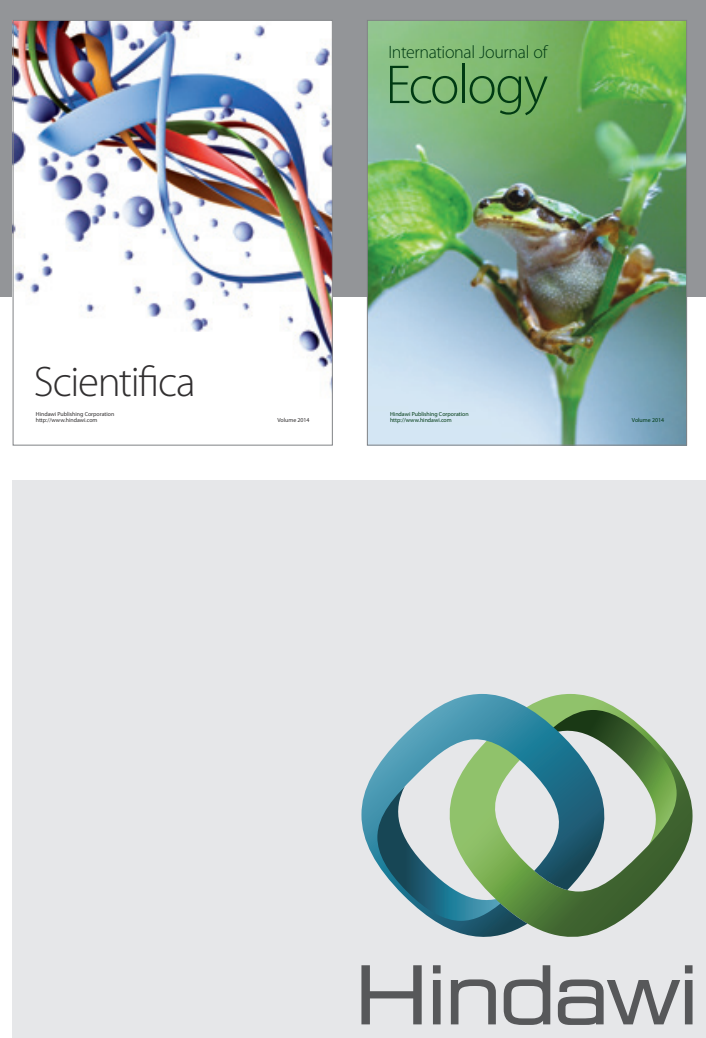

Submit your manuscripts at

http://www.hindawi.com
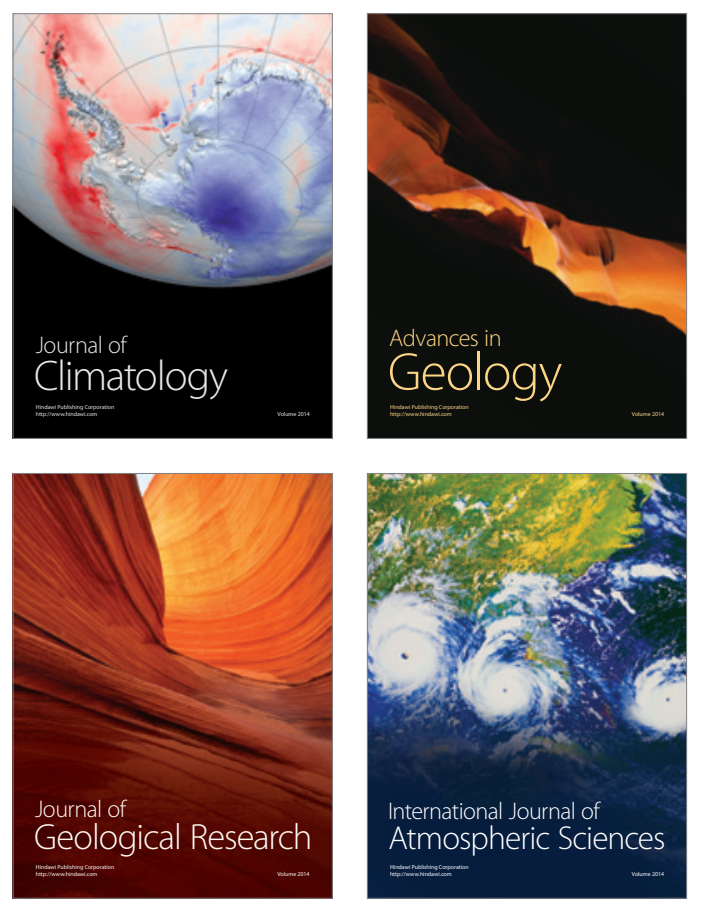

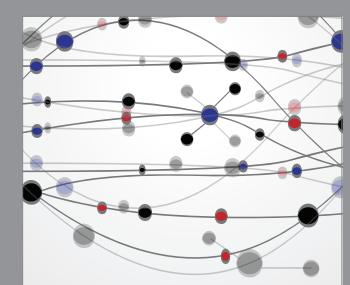

The Scientific

\section{World Journal}
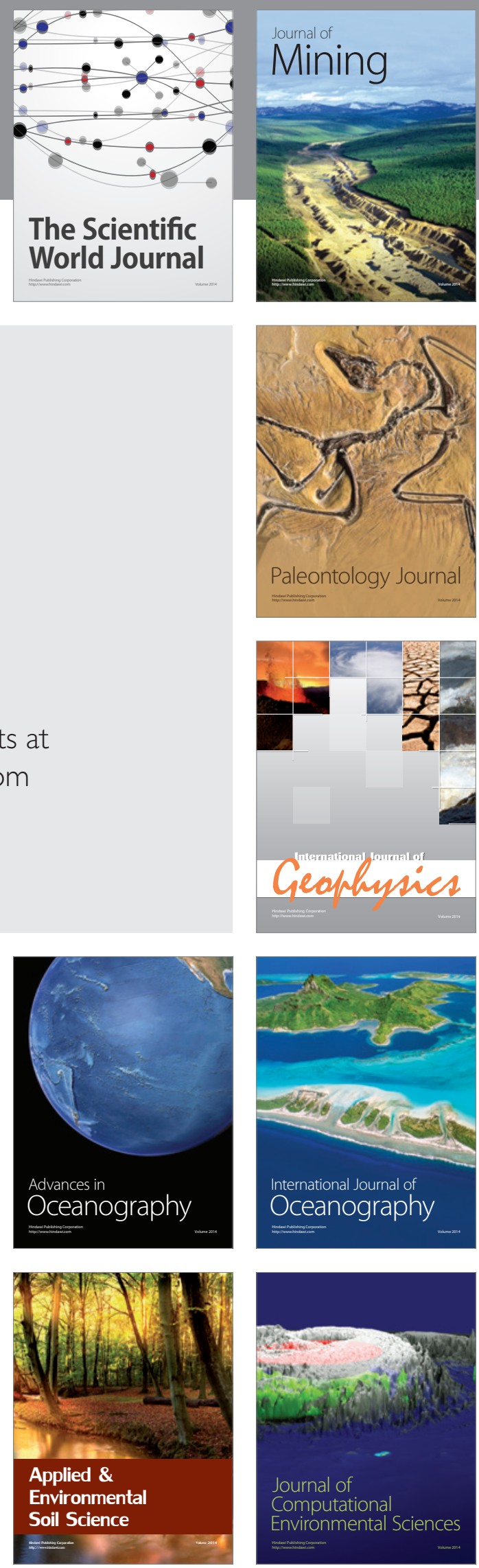